\title{
What Leads to Persisting Surface Air Temperature Anomalies from Winter to Following Spring over Mid- to High-Latitude Eurasia?
}

\author{
RENGUANG WU \\ School of Earth Sciences, Zhejiang University, Hangzhou, and Center for Monsoon System Research, Institute of \\ Atmospheric Physics, Chinese Academy of Sciences, Beijing, China \\ SHANGFENG CHEN \\ Center for Monsoon System Research, Institute of Atmospheric Physics, Chinese Academy of Sciences, and College of Earth \\ Sciences, University of Chinese Academy of Sciences, Beijing, China
}

(Manuscript received 28 October 2019, in final form 18 January 2020)

\begin{abstract}
Surface air temperature (SAT) anomalies tend to persist from winter to the following spring over the mid- to high latitudes of Eurasia. The present study compares two distinct cases of Eurasian SAT anomaly evolution and investigates the reasons for the persistence of continental-scale mid- to high-latitude Eurasian SAT anomalies from winter to following spring (termed persistent cases). The persisting SAT anomalies are closely associated with the sustenance of large-scale atmospheric circulation anomaly pattern over the North Atlantic and Eurasia, featuring a combination of the North Atlantic Oscillation/Arctic Oscillation (NAO/AO) and the Scandinavian pattern, from winter to spring. The combined circulation anomalies result in SAT warming over most of mid- to high-latitude Eurasia via anomalous wind-induced temperature advection. The sustenance of atmospheric circulation anomaly pattern is related to the maintenance of the North Atlantic triple sea surface temperature (SST) anomaly pattern due to air-sea interaction processes. The Barents Sea ice anomalies, which form in winter and increase in spring, also partly contribute to the sustenance of atmospheric circulation anomalies via modulating thermal state of the lower troposphere. In the cases that notable SAT warming (cooling) in winter is replaced by pronounced SAT cooling (warming) in the subsequent spring-termed reverse cases-the North Atlantic SST anomalies become small and the Greenland Sea ice change is a response to atmospheric change in spring. Without the support of lower boundary forcing, the atmospheric circulation anomaly pattern experiences a reverse in the spatial distribution from winter to spring likely due to internal atmospheric processes.
\end{abstract}

\section{Introduction}

Abnormal surface temperature exerts substantial impacts on the crop growth, ecosystem, human health, and socioeconomic development (Sun et al. 1983; Yao 1995; Beniston 2004; Labat et al. 2004; Stott et al. 2004; Wang et al. 2011; Chen et al. 2016). For instance, the recordbreaking cold winter of 2009/10 over Eurasia and cold winter of 2008 over southern China led to increased transportation costs and excessive energy consumption and significantly influenced people's daily activities (Bao et al. 2010; Otomi et al. 2013). Eurasian surface temperature changes may modulate the thermal contrast between the Eurasian continent and surrounding oceans

Corresponding author: Dr. Shangfeng Chen, chenshangfeng@ mail.iap.ac.cn and thus affect the Asian monsoon intensity (e.g., Liu and Yanai 2001). Given the large impacts of surface temperature anomalies, it is of great importance to understand the spatial-temporal characteristics and the factors of surface temperature anomalies over the Eurasian continent.

Several previous studies have investigated the dominant modes of surface air temperature (SAT) variations over the mid- to high latitudes of Eurasia in winter and spring (Miyazaki and Yasunari 2008; Gámiz-Fortis et al. 2011; Chen et al. 2016; Chen and Wu 2017, 2018). The leading mode of winter and spring SAT variations is characterized by a same-sign loading pattern (Miyazaki and Yasunari 2008; Zveryaev and Gulev 2009; Gámiz-Fortis et al. 2011; Chen et al. 2016; Chen and Wu 2017, 2018). Most previous studies focused on the Eurasian SAT variations in winter and spring separately. The impacts of SAT anomalies likely depend upon the time period of persistence. A question is 
whether the Eurasian SAT anomalies can persist from winter to following spring and what the conditions are leading to persistent SAT anomalies. Understanding the persistence of SAT anomalies in winter-spring and the factors would have an important implication for the seasonal prediction of SAT variations. This motivates the present study.

Studies indicated that SAT variations over Eurasia are impacted by several atmospheric circulation patterns, including the Arctic Oscillation (AO)/North Atlantic Oscillation (NAO) and the Scandinavian pattern (Thompson and Wallace 1998; Gong et al. 2001; Barnston and Livezey 1987; Zveryaev and Gulev 2009; Cheung et al. 2012; Chen et al. 2018a, 2019a; Chen and Song 2019). During the positive (negative) phase of the NAO/AO, most parts of mid- to high-latitude Eurasia are dominated by positive (negative) SAT anomalies (Thompson and Wallace 1998; Gong et al. 2001; Chen et al. 2016). For persistent winter-to-spring SAT anomalies, the atmospheric circulation anomaly pattern needs to be maintained from winter to spring. A question is under what conditions similar atmospheric circulation anomaly patterns may be maintained for two seasons. As the internal atmospheric processes cannot account for such persistence, the external forcing may play an important role in the sustenance of similar atmospheric circulation patterns.

Previous studies have illustrated the impacts on Eurasian winter and spring SAT variations of the North Atlantic sea surface temperature (SST) (Chen et al. 2016; Chen and Wu 2017; Chen et al. 2019a), the Arctic sea ice concentration (SIC) (Wu et al. 2011; Francis and Vavrus 2012; Li and Wu 2012; Liu et al. 2012; Tang et al. 2013; Z. Chen et al. 2014; Sun et al. 2016; Chen and Wu 2018; Chen and Song 2019; Li et al. 2019; Chen et al. 2019b), and the Eurasian snow cover (Cohen and Fletcher 2007; Cohen et al. 2012; Chen et al. 2016; Wu and Chen 2016). The North Atlantic SST anomalies can exert large impacts on the Eurasian spring SAT variation via atmospheric teleconnection (Chen et al. 2016; Chen and Wu 2017). The autumn-winter Arctic SIC changes may induce winter and spring Eurasian surface temperature anomalies through modulating the Siberian high via the atmospheric wave train (Wu et al. 2011; Sun et al. 2016; Wu et al. 2016) or inducing a NAO/AO-like atmospheric anomalies via stratospheric processes (Nakamura et al. 2015; Yang et al. 2016; Chen and Wu 2018). The preceding autumn snow cover change over Eurasia can impact following winter $\mathrm{NAO} / \mathrm{AO}$ and SAT over Eurasia via stratospheric teleconnection (Cohen and Fletcher 2007; Cohen et al. 2012). A question is what type of lower boundary condition plays the most important role in the maintenance of atmospheric circulation anomaly pattern and Eurasian SAT anomalies from winter to spring.

In this study, we will show that the continental-scale SAT anomalies in winter over the mid- to high latitudes of Eurasia can be maintained to the following spring in many years. However, there exist a number of years when marked winter SAT warming (cooling) over Eurasia is followed by large SAT cooling (warming) in the subsequent spring. We will compare the above two types of SAT anomaly evolutions from winter to following spring and investigate the factors for the distinct SAT anomaly evolutions. We will show that the North Atlantic SST and Arctic SIC anomalies are important for the distinctive evolutions of atmospheric circulation and associated SAT anomalies over Eurasia.

The rest of the paper is structured as follows. Section 2 describes the data and methods used in the present study. Section 3 compares two types of SAT anomaly evolutions from winter to following spring and the associated atmospheric circulation changes. Sections 4 and 5 investigate the roles of the North Atlantic SST and the Arctic SIC changes, respectively, in the different SAT anomaly evolutions. Section 6 summarizes the key findings of this study and provides a discussion of relevant issues.

\section{Data and methods}

The present study uses monthly mean SAT of the University of Delaware air temperature and precipitation dataset, version v5.01, from January 1900 to December 2017 with a horizontal resolution of $0.5^{\circ} \times 0.5^{\circ}$ (Matsuura and Willmott 2009), obtained from https://www.esrl.noaa. gov/psd/data/gridded/data.UDel_AirT_Precip.html. The monthly mean SST data used in the present study are extracted from the National Oceanic and Atmospheric Administration (NOAA) Extended Reconstructed SST version 3b (ERSSTv3b) and version 5 (Smith et al. 2008; Huang et al. 2017), which are available at https:// www.esrl.noaa.gov/psd/data/gridded/. These two SST datasets both have a horizontal resolution of $2^{\circ} \times 2^{\circ}$ and span from January 1854 to the present. The results based on the above two SST datasets are very similar. We only show the results based on the ERSSTv5 SST. Monthly mean SIC data are derived from the Hadley Centre Sea Ice and Sea Surface Temperature dataset (HadISST) (Rayner et al. 2003), obtained via https:// www.metoffice.gov.uk/hadobs/hadisst/. This SIC dataset covers the period from January 1870 to the present and is available on a horizontal resolution of $1^{\circ} \times 1^{\circ}$ in the longitude-latitude grid. The snow cover extent data are extracted from the Northern Hemisphere 25-km Equal-Area Scalable Earth Grid (EASE-Grid) weekly Snow Cover and Sea Ice Extent version 3, obtained via ftp://sidads.colorado.edu/pub/DATASETS (Brodzik and Armstrong 2013). The raw weekly SCE has been converted to monthly mean on a horizontal resolution of $1^{\circ} \times 1^{\circ}$ in longitude-latitude grid. 
The present study uses monthly mean geopotential height and horizontal winds from the National Centers for Environmental Prediction-National Center for Atmospheric Research (NCEP-NCAR) reanalysis dataset, which are available since January 1948 (Kalnay et al. 1996) via ftp:// ftp.cdc.noaa.gov/Datasets/ncep.reanalysis.derived/. The NCEP-NCAR reanalysis data have a horizontal resolution of $2.5^{\circ} \times 2.5^{\circ}$ in the longitude-latitude grid.

The monthly mean NAO, AO, and Scandinavian (SCAND) teleconnection indices are extracted from the National Oceanic and Atmospheric Administration Climate Prediction Center and are available from January 1950 to the present (https://www.cpc.ncep.noaa.gov/ data/teledoc/telecontents.shtml). The AO is the leading atmospheric interannual variability over the Northern Hemisphere. Studies indicate that NAO can be considered as the regional manifestation of $\mathrm{AO}$ over the North Atlantic region (Hurrell 1995; Hurrell and van Loon 1997; Thompson and Wallace 1998). The AO includes most characteristics of the NAO (Thompson and Wallace 2000). The NAO/AO has a barotropic vertical structure and is featured by an oscillation in sea level pressure and geopotential height anomalies between subtropical and mid- to high latitudes of the North Atlantic (Hurrell 1995; Hurrell and van Loon 1997; Thompson and Wallace 1998, 2000). The SCAND pattern is one of the prominent atmospheric wave trains over Eurasia, with one center of action around Scandinavia and two opposite-sign centers of action over eastern Russia/western Mongolia and western Europe (Barnston and Livezey 1987). The AO/NAO and SCAND pattern are important atmospheric intrinsic modes. Intrinsic atmospheric processes play a dominant role in the AO/NAO and SCAND variations from intraseasonal to interannual time scales (Barnston and Livezey 1987; Lau 1988; Limpasuvan and Hartmann 1999; Lorenz and Hartmann 2003).

This study concentrates on the variations on the interannual time scale. A 2-9-yr Lanczos filter is applied to all the variables to exclude the long-term trends and interdecadal variations (Duchon 1979), following previous studies (Chen et al. 2016, 2019b). We have calculated the percent variances of the unfiltered (but long-term trends have been removed; denoted by detrended) SAT, SST, and SIC variations explained by their interannual components during winter and spring. Results show that the interannual SAT anomalies can explain above $80 \%$ of the variance of the detrended SAT anomalies over most parts of Eurasia (figures not shown). Interannual SST (SIC) anomalies explain above $60 \%$ (70\%) of the variance of the detrended SST (SIC) anomalies over most North Atlantic (Arctic) regions (figures not shown). An empirical orthogonal function (EOF) analysis is used to extract the dominant modes of SAT variations. Correlation and composite analyses are employed in the present study. Statistical significance of correlation coefficient and anomalies obtained from composite and regression analyses is estimated according to a two-tailed Student's $t$ test. We note that the results obtained based on the detrended data are similar.

\section{Evolutions of Eurasian SAT and atmospheric circulation anomalies}

In this section, we first examine the dominant modes of SAT anomalies over the mid- to high latitudes of Eurasia in boreal winter [December-February (DJF)] and spring [March-May (MAM)] via an EOF method. Then, we compare two different evolutions of SAT anomalies over Eurasia from winter to following spring via composite analysis. After that, we analyze the evolution of associated atmospheric circulation anomalies in the two types of years.

The leading mode (EOF1) of SAT anomalies displays a continental-scale warming/cooling pattern over mid- to high-latitude Eurasia in both winter and spring, with maximum anomalies located around central Siberia (Figs. 1a,b). The EOF1 of winter and spring Eurasian SAT anomalies explains $46.5 \%$ and $41.6 \%$ of the total interannual variance, respectively. EOF1 is well separated from other EOF modes for both winter and spring according to the method of North et al. (1982). The correlation coefficient between PC1s in winter and spring (Figs. 1c,d) is about 0.29 during 1949-2017, significant at the 99\% confidence level. This suggests a tendency for the large-scale SAT warming/ cooling over mid- to high-latitude Eurasia to persist from winter to following spring.

Detailed comparison of the winter and spring PC1 variations indicates that in addition to the in-phase variations of $\mathrm{PC} 1$ in winter and spring, there exist a number of years when the winter and spring PC1s are out of phase. In these years, positive (negative) winter SAT anomalies over Eurasia are followed by negative (positive) spring SAT anomalies. For example, in 1952, the DJF PC1 is significantly positive, whereas the MAM $\mathrm{PC} 1$ is significantly negative. This is in sharp contrast to an in-phase year (e.g., 1969), when SAT anomalies are significantly negative in both winter and spring. Here, we define a positive (negative) phase of the winter and spring PC1 when the standardized PC1 is above (below) $0.43(-0.43)$ standard deviations. The value of \pm 0.43 standard deviation provides a classification of three categories (negative, normal, and positive phases) with almost the same sample numbers (i.e., 33\% each) (Park and Ahn 2015; Chen et al. 2018a). A use of 0.5 standard deviations as the threshold does not change the results in 

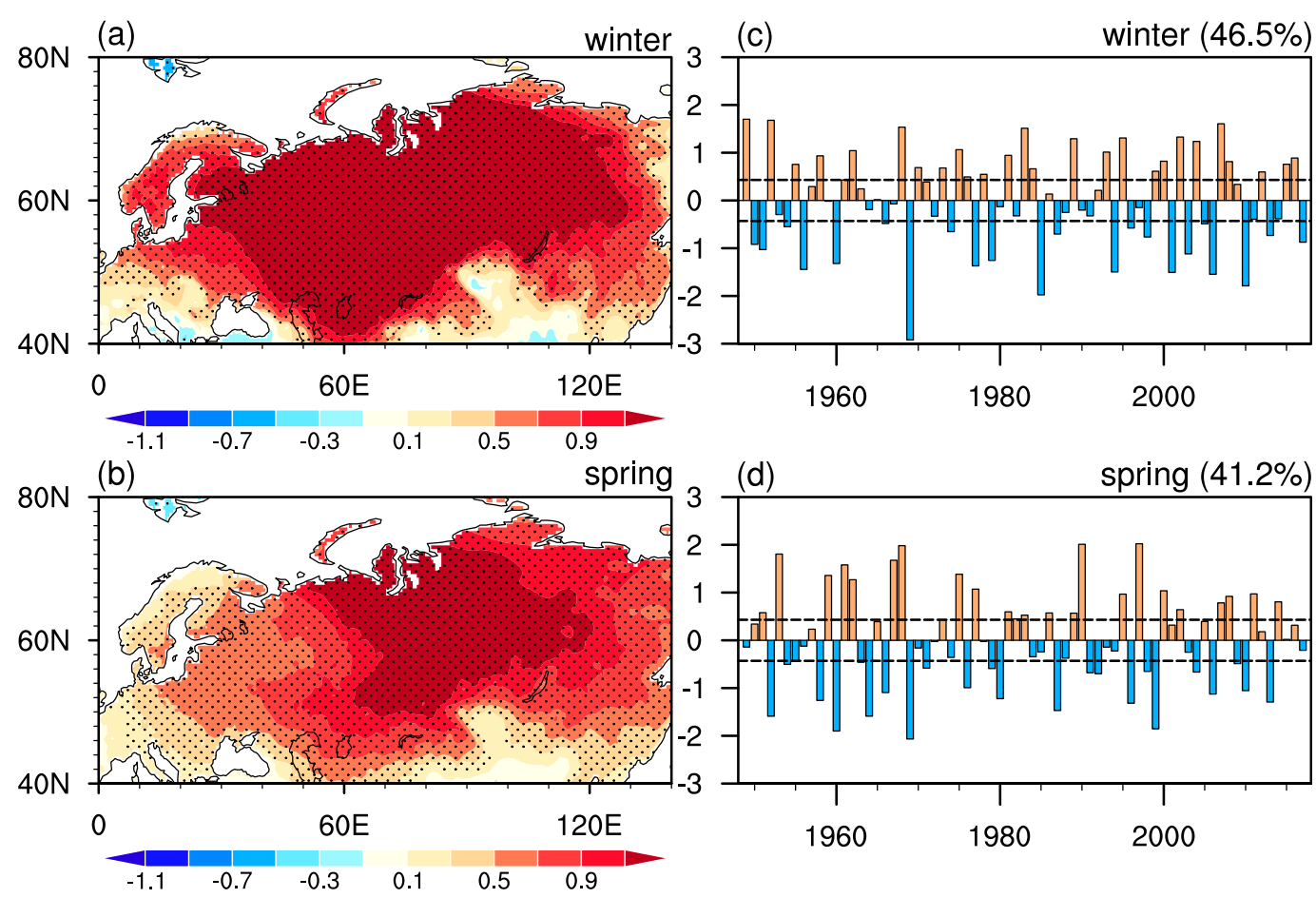

FIG. 1. (a) SAT anomalies $\left({ }^{\circ} \mathrm{C}\right)$ in winter regressed upon the normalized PC time series corresponding to the EOF1 of winter SAT anomalies over the mid- to high-latitude Eurasia for the period 1949-2017. (c) The normalized PC time series corresponding to the EOF1 of winter SAT anomalies over mid- to high-latitude Eurasia. (b),(d) As in (a) and (c), but for SAT anomalies in the following spring. The horizontal dashed lines in (b) and (d) denote the value of \pm 0.43 .

this study. Table 1 lists the years when winter and spring $\mathrm{PC} 1 \mathrm{~s}$ are out of phase and in phase, respectively. From Table 1, it is clear that there are more in-phase cases than out-of-phase cases, consistent with the fact that winter and spring PC1s have a significant positive correlation. The correlation coefficient between the $\mathrm{PC} 1$ of winter and spring SAT anomalies is about 0.51 after exclusion of the reverse cases (a total of 61 years). In brief, in-phase (out-of-phase) cases are called persistent (reverse) cases. In the following, we compare the temporal evolutions of composite SAT and atmospheric circulation anomalies in the two types of cases. In constructing the composite anomalies, we have reversed the anomalies when the winter PC1 is negative as winter

TABLE 1. Years when winter and spring SAT anomalies over mid- to high-latitude Eurasia have the same sign (i.e., persistent cases) and the opposite sign (i.e., reverse cases).

Persistent cases $1954,1960,1962,1966,1968,1969,1975$ 1979, 1981, 1983, 1987, 1989, 1995, 1996, 1998, 2000, 2002, 2006, 2007, 2008, 2010, 2013

Reversed cases 1951, 1952, 1955, 1958, 1976, 1977, 1999, 2004 atmospheric circulation and SAT anomalies over the North Atlantic and Eurasia, to a large extent, are symmetric between negative and positive phases of the winter PC1. The descriptions in the following correspond to positive winter SAT anomalies.

In the persistent cases, significant positive SAT anomalies are observed over most parts of mid- to high-latitude Eurasia in winter, with maximum anomalies of above $1.8^{\circ} \mathrm{C}$ extending eastward from the eastern European plain to central Siberia (Fig. 2a). The continental-scale positive SAT anomalies are maintained to the following spring with weakening in the magnitude of anomalies and an eastward displacement of the region with large anomalies (Figs. 2b-d). In the reverse cases, there is pronounced warming in winter over mid- to high-latitude Eurasia except for a small patch of cooling around southern Europe (Fig. 2e). Winter SAT anomalies are weak and insignificant over western Europe (Fig. 2e). In the following months, the positive SAT anomalies over central Eurasia decrease (Figs. 2f,g). In spring, notable negative SAT anomalies develop covering most portions of Eurasia with maximum amplitude of about $1.8^{\circ} \mathrm{C}$ (Fig. 2h).

Studies have demonstrated that atmospheric circulation anomalies play an important role in the formation 

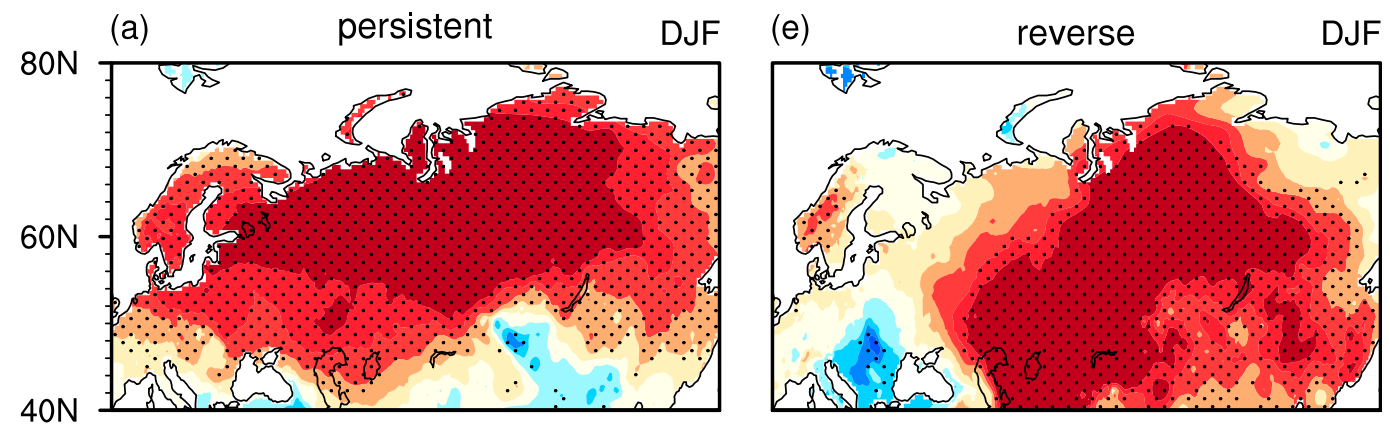

(b) JFM $(f)$
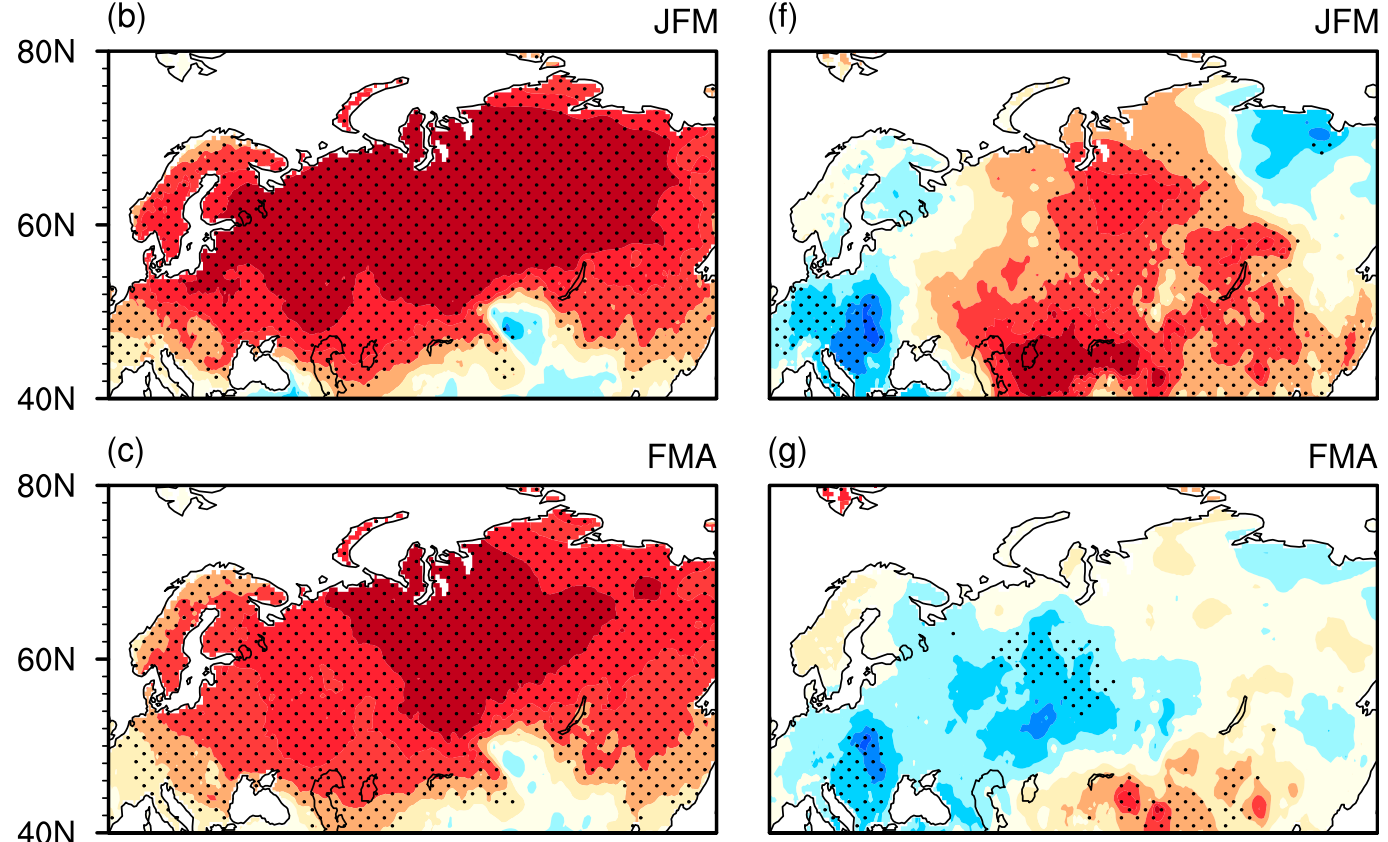

(g)

FMA

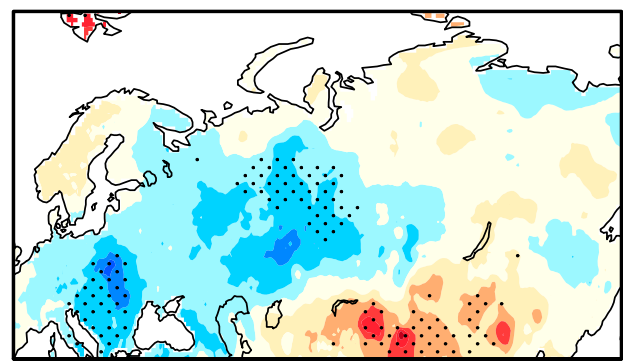

(d)

(h)
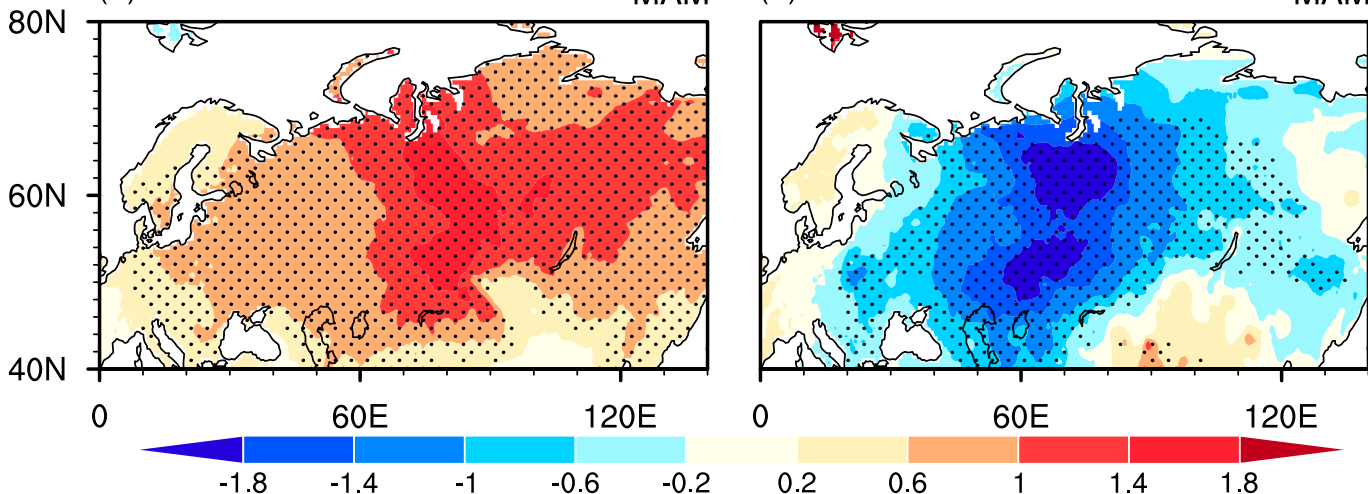

FIG. 2. Composite anomalies of SAT $\left({ }^{\circ} \mathrm{C}\right)$ in (a),(e) December-February (DJF), (b),(f) January-March (JFM), (c),(g) February-April (FMA), and (d),(h) March-May (MAM) in (left) the persistent cases and (right) the reverse cases. The stippled region indicates anomalies significant at the $95 \%$ confidence level.

and change of the SAT anomalies over the mid- to high latitudes of Eurasia (Miyazaki and Yasunari 2008; Wu et al. 2010; Cheung et al. 2012; Chen et al. 2016, 2018a,b, 2019a). Thus, it is expected that the maintenance or switch of SAT anomalies is associated with that of atmospheric circulation anomaly pattern. This is illustrated by the distinct spatial distribution and temporal evolution of composite anomalies of $850-\mathrm{hPa}$ winds 

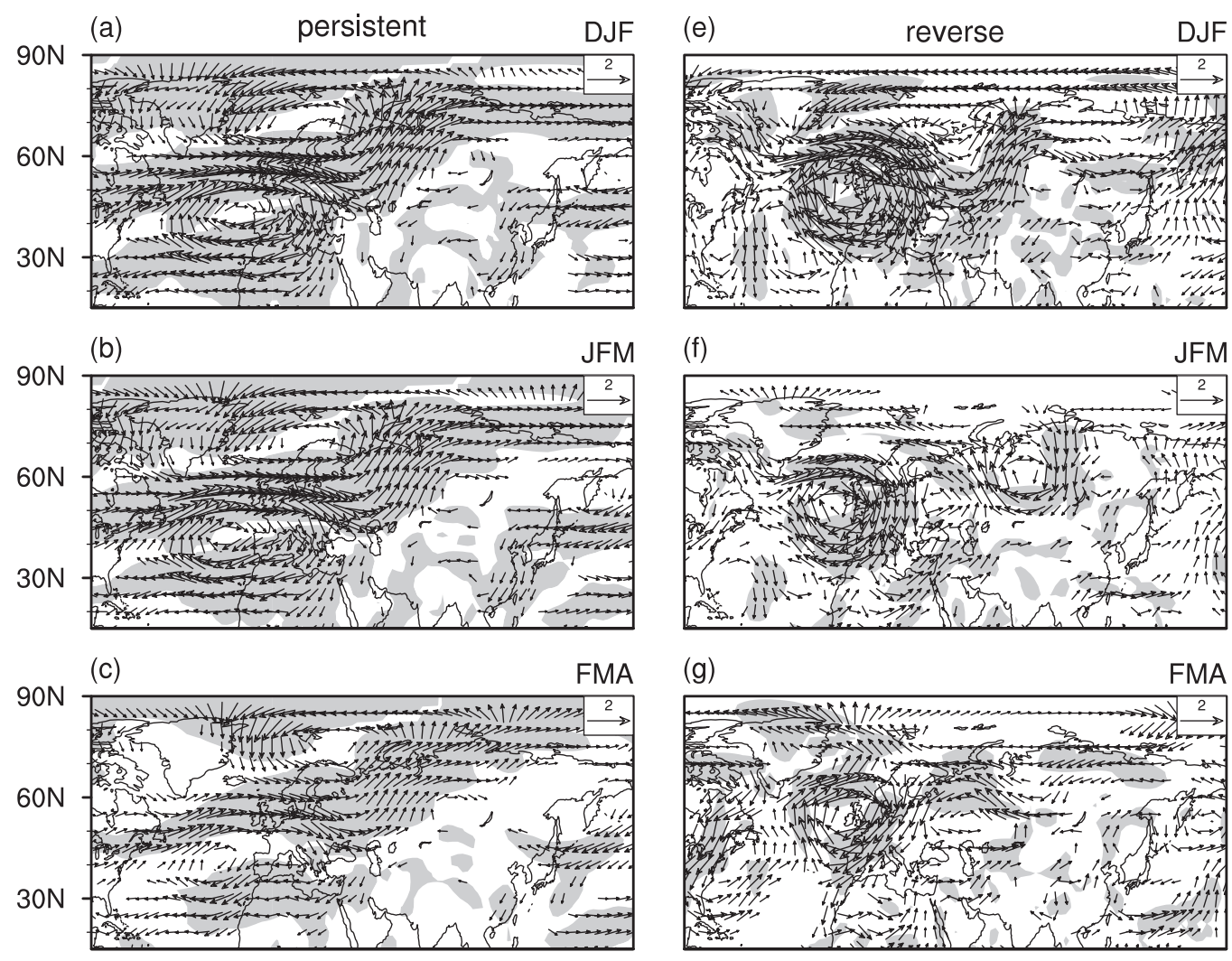

(g)

FMA
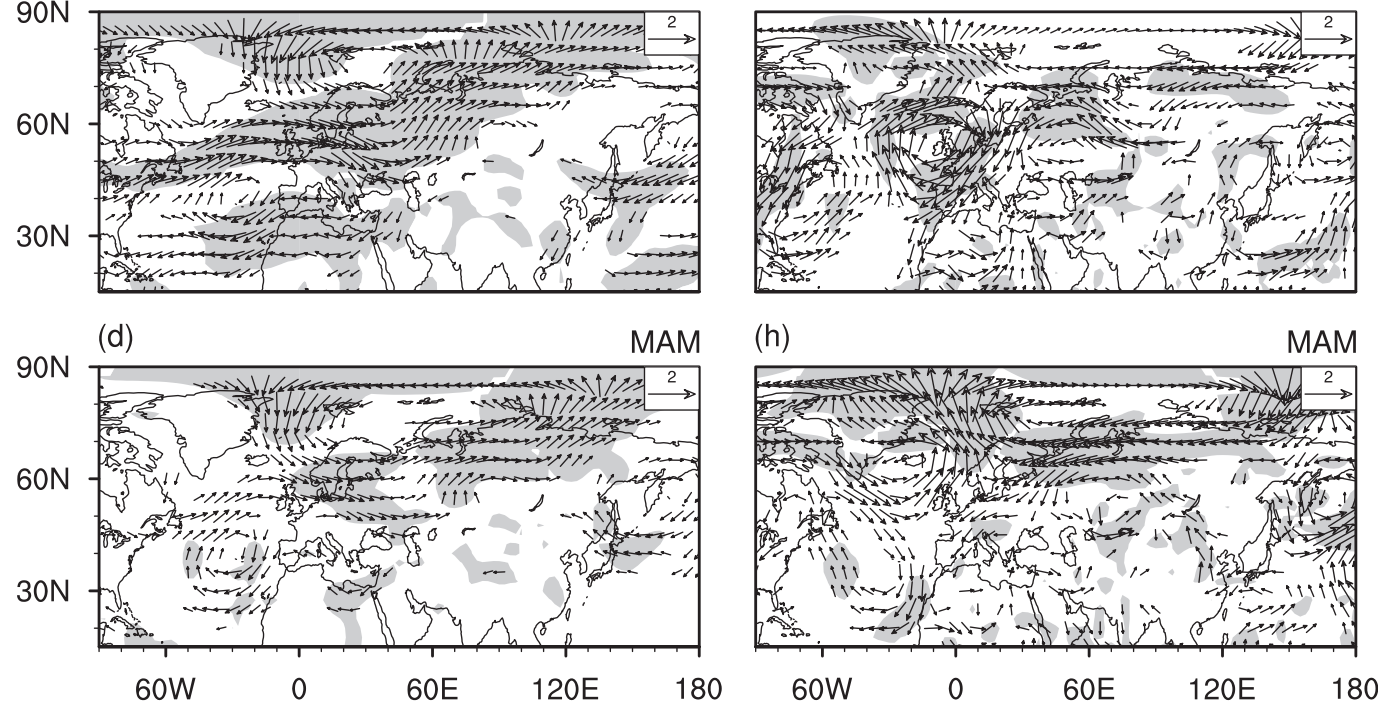

FIG. 3. Composite anomalies of 850-hPa winds $\left(\mathrm{m} \mathrm{s}^{-1}\right.$ ) in (a),(e) DJF, (b),(f) JFM, (c),(g) FMA, and (d),(h) MAM in (left) the persistent cases and (right) the reverse cases. Shading region indicates either direction of wind anomalies significant at the $95 \%$ confidence level. Wind anomalies in both directions less than $0.3 \mathrm{~m} \mathrm{~s}^{-1}$ are omitted.

from winter to following spring in the persistent and reverse cases.

In the persistent cases, an anomalous anticyclone is observed over subtropical North Atlantic and an anomalous cyclone controls the northern North Atlantic in winter (Fig. 3a). The above wind anomalies feature a positive phase of the NAO/AO (Hurrell 1995; Thompson and Wallace 1998). Strong westerly wind anomalies extend from the midlatitude North Atlantic to western Europe (Fig. 3a). These westerly wind anomalies bring warmer air from the North Atlantic to Europe (Fig. 3a), explaining the SAT increase there (Fig. 2a). In addition, southwesterly wind anomalies over mid- to high-latitude
Eurasia (Fig. 3a) contribute to surface warming via carrying warmer air from lower latitudes (Chen et al. 2016, 2018b). The above lower-level wind anomalies are maintained to following spring albeit with some weakening and eastward movement (Figs. 3a-d). This favors the maintenance of SAT anomalies from winter to following spring (Figs. 2a-d).

In the reverse cases, a marked anomalous anticyclone is present over the subtropical North Atlantic in winter (Fig. 3e). In comparison, the location of the anomalous anticyclone shifts slightly northward compared to that in the persistent cases (Fig. 3a). The anomalous northerly winds along its northeastern flank (Fig. 3e) may explain 

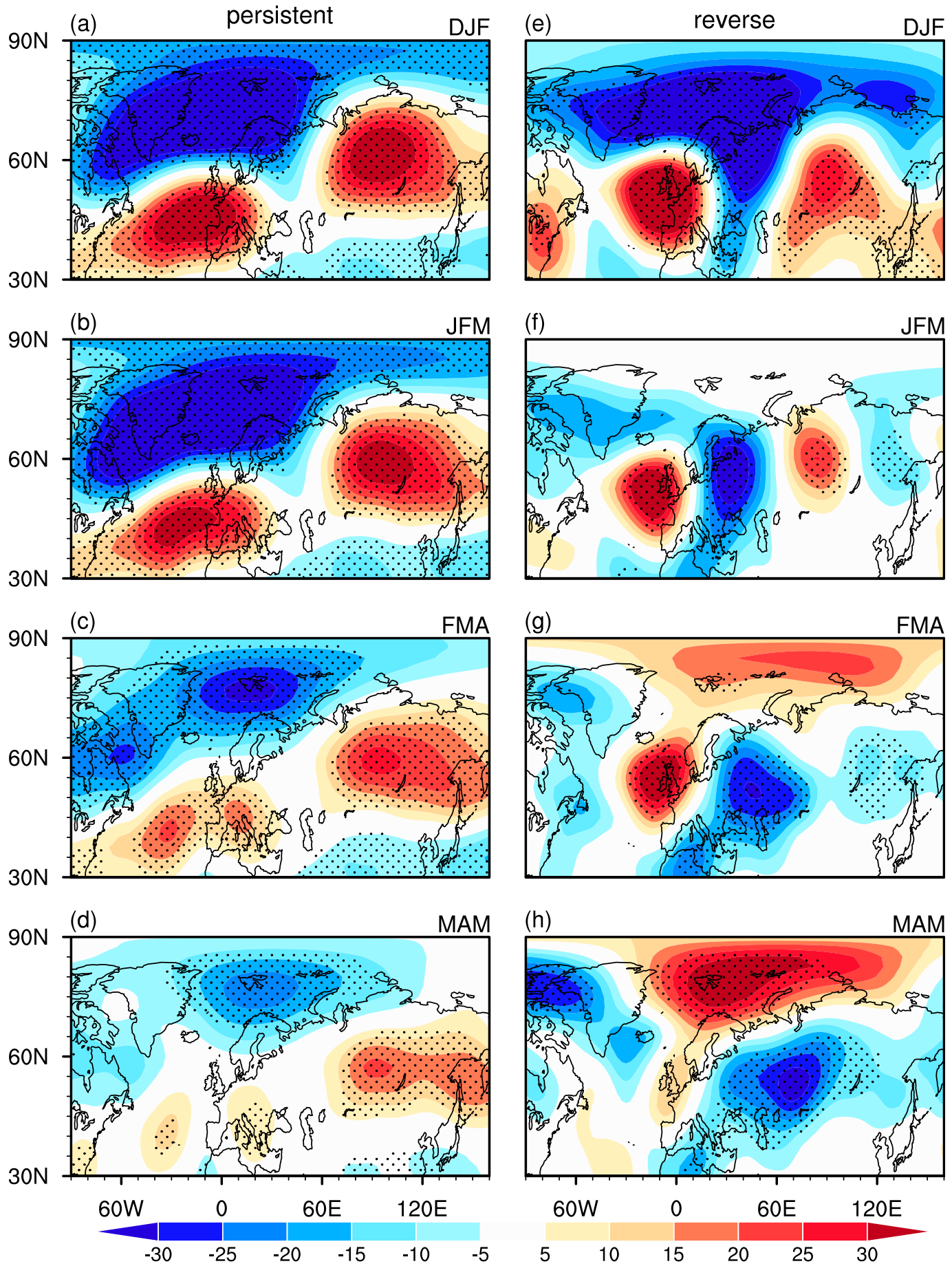

FIG. 4. Composite anomalies of 500-hPa geopotential height (m) in (a),(e) DJF, (b),(f) JFM, (c),(g) FMA, and (d),(h) MAM for (left) the persistent cases and (right) the reverse cases. The stippled region indicates anomalies significant at the $95 \%$ confidence level.

negative SAT anomalies over south Europe via carrying colder air from higher latitudes (Fig. 2e). A pronounced anomalous cyclone controls the high latitudes of Europe with marked southwesterly wind anomalies over mid- to high-latitude Eurasia (Fig. 3e). This leads to SAT increase over Eurasia via anomalous wind-induced horizontal temperature advection (Fig. 2e) (Chen et al. 2016, 2019a). The anomalous anticyclone over the subtropical 

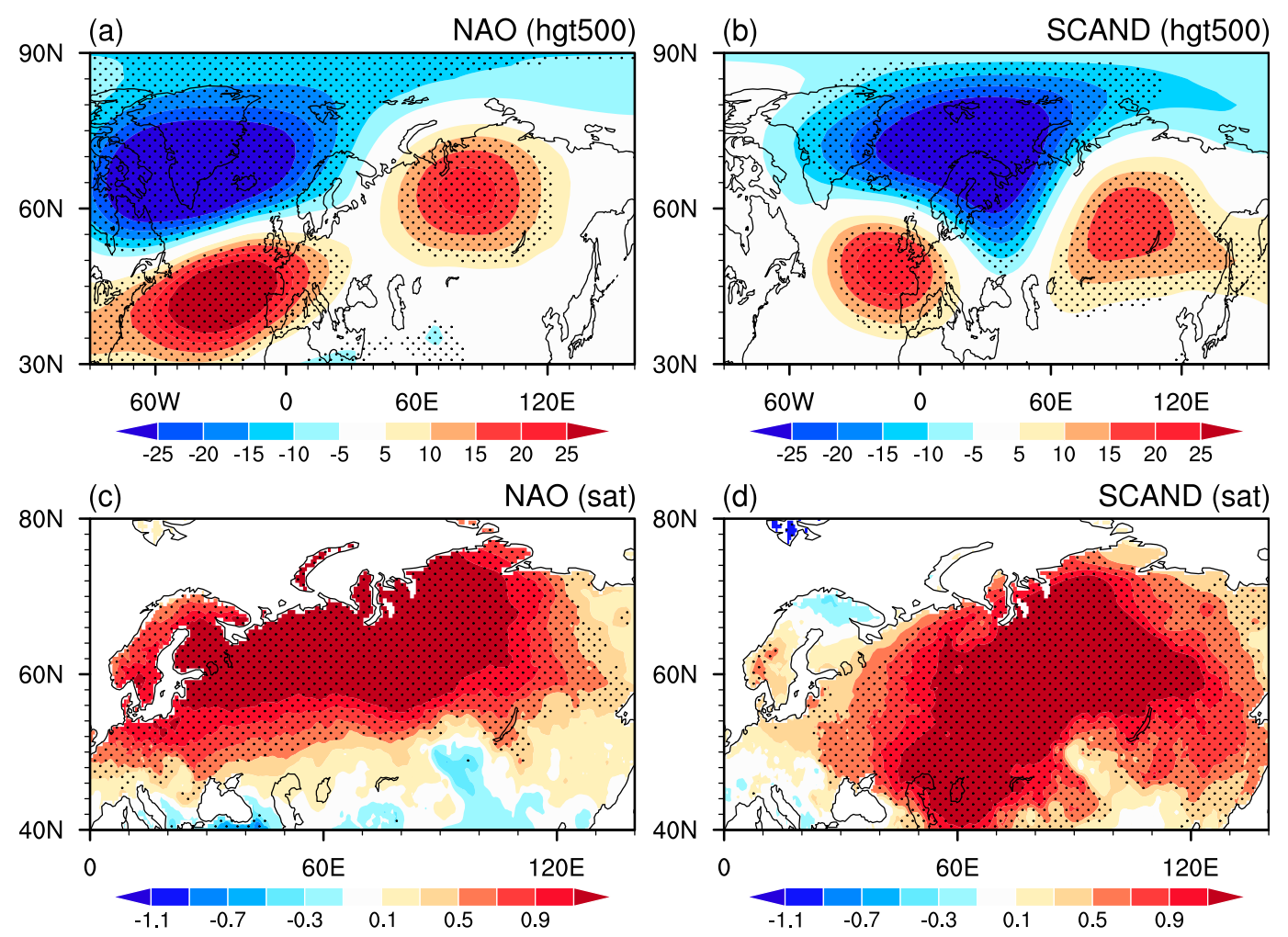

FIG. 5. Regression maps of (a) 500-hPa geopotential height (m) and (c) SAT anomalies $\left({ }^{\circ} \mathrm{C}\right)$ in winter onto the normalized winter (left) NAO and (right) Scandinavian teleconnection index over 1949-2017. The stippled region indicates anomalies significant at the $95 \%$ confidence level.

North Atlantic is maintained for two months (Figs. 3e-g) and disappears in spring (Fig. 3h). The marked cyclonic anomaly over the high latitudes in DJF is replaced by a strong anticyclonic anomaly in MAM (Figs. 3e-h). With the development of an anomalous anticyclone over Siberia (Fig. 3f), northeasterly wind anomalies develop and expand to cover the high latitudes of Eurasia in the following spring (Fig. 3h), which lead to negative SAT anomalies through carrying colder air from higher latitudes (Fig. 2h) (Chen et al. 2016, 2018a).

Distinct spatial distribution and temporal evolution are also seen in composite anomalies of 500-hPa geopotential height. The distribution of composite 500-hPa geopotential height anomalies is similar to that of composite $850-\mathrm{hPa}$ wind anomalies over the mid- to high latitudes of the North Atlantic and Eurasia, indicating a barotropic vertical structure, consistent with previous studies (Chen et al. 2016; Chen and Wu 2017). In the persistent cases, the geopotential height anomalies in winter display a dipole pattern over the North Atlantic with pronounced positive anomalies over the subtropics and negative anomalies over the high latitudes (Fig. 4a). In addition, negative geopotential height anomalies extend to the Arctic region. The above distribution of geopotential height anomalies bears a close resemblance to that of the positive winter
NAO/AO phase (Hurrell 1995; Thompson and Wallace 1998, 2000). The distribution of the winter geopotential height anomalies in Fig. 4a is also similar to that related to the winter SCAND pattern (Barnston and Livezey 1987; Chen et al. 2018a).

The above similarity of the distribution of geopotential height anomalies to the NAO/AO and SCAND patterns indicates the role of the NAO/AO and SCAND pattern in the formation of Eurasian SAT anomalies in the persistent cases. To confirm this, we obtain geopotential height and SAT anomalies by regression with respect to the NAO/ AO and SCAND indices. Notable surface warming is observed over Eurasia corresponding to positive NAO/ AO phase (Fig. 5c), consistent with previous studies (Hurrell 1995; Thompson and Wallace 1998, 2000; Gong et al. 2001; Chen et al. 2016, 2018a). Positive SAT anomalies are seen over most parts of mid- to high-latitude Eurasia corresponding to positive SCAND index (Fig. 5d). Note that the spatial pattern of the SAT anomalies related to the winter SCAND index (Fig. 5d) shifts southeastward compared to the winter NAO-related one (Fig. 5c). The pattern correlation coefficient of geopotential height anomalies presented in Fig. 4a with the winter NAOrelated geopotential height anomalies in Fig. 5a reaches 0.89 over the domain of $30^{\circ}-90^{\circ} \mathrm{N}$ and $90^{\circ}-150^{\circ} \mathrm{W}$. The 
pattern correlation coefficient of geopotential height anomalies in Fig. 4a with the winter SCAND pattern in Fig. $5 b$ is about 0.84 . Correlation coefficients of winter PC1 with winter NAO and SCAND indices are 0.68 and 0.57 , respectively, during 1949-2017, both significant at the $99 \%$ confidence level. The above analysis indicates that the formation of the continental-scale winter warming over the mid- to high latitudes of Eurasia is due to a combined effect of the winter NAO and SCAND pattern. The 500$\mathrm{hPa}$ geopotential height anomaly pattern is maintained to the following spring (Figs. 4a-d), consistent with the 850hPa wind anomalies (Figs. 3a-d).

In the reverse cases, the winter geopotential height anomalies over the North Atlantic and Eurasia (Fig. 4e), as well as the winter SAT anomalies over Eurasia (Fig. 2e), are more similar to those related to the winter SCAND index (Figs. 5b,d) than the winter NAO index (Figs. 5a,c). The pattern correlation coefficient of the winter geopotential height anomalies in Fig. 4e with those related to the winter SCAND (NAO) index is about $0.88(0.50)$ over the domain of $30^{\circ}-90^{\circ} \mathrm{N}$ and $90^{\circ}-150^{\circ} \mathrm{E}$. While the positive height anomalies over the west coast of Europe tend to persist, the positive height anomalies to the northwest of the Lake Baikal decrease and the negative height anomalies over eastern Europe move eastward and expand in areal extent following the weakening and switch of height anomalies in the Arctic region (Figs. 4e-h). In spring, negative height anomalies dominate Eurasia and the Arctic region is under the control of positive height anomalies (Fig. 4h). The above change of $500-\mathrm{hPa}$ geopotential height anomalies is consistent with that of $850-\mathrm{hPa}$ wind anomalies.

The distinct temporal evolution of Eurasian SAT anomalies and the AO and SCAND pattern is further illustrated in Fig. 6. In the persistent cases, the Eurasian SAT anomalies increase in preceding fall, reach the peak in late winter, and maintain to the following spring with a decrease of magnitude (Fig. 6a). The AO is maintained in the positive phase during preceding fall to the following spring (Fig. 6b). The SCAND pattern develops in late fall, reaches the peak in late winter, and weakens in spring (Fig. 6c). In the reverse cases, the Eurasian SAT anomalies reach the peak in winter, weaken thereafter, and switch the sign in early spring (Fig. 6a). The AO is significantly positive during fall and winter, but becomes small starting in late winter (Fig. 6b). The SCAND pattern is in the positive phase during fall and winter and switches to the negative phase in early spring (Fig. 6c).

\section{Role of the North Atlantic SST anomalies}

The analysis in the previous section indicates that temporal evolutions of the Eurasian SAT anomalies are (a)

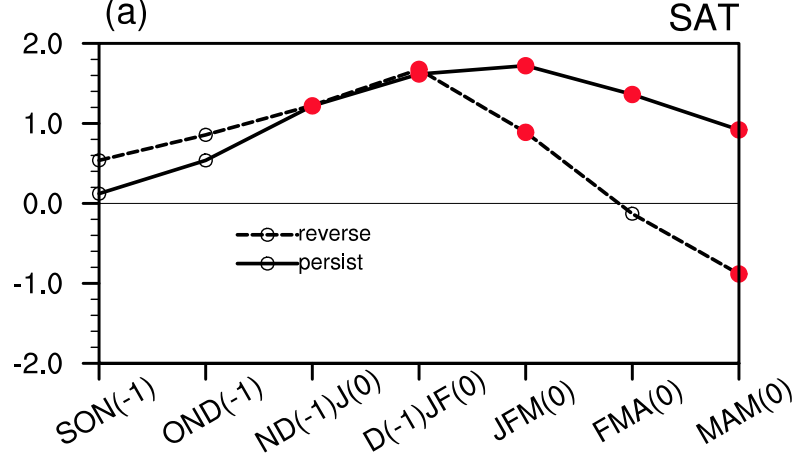

(b)

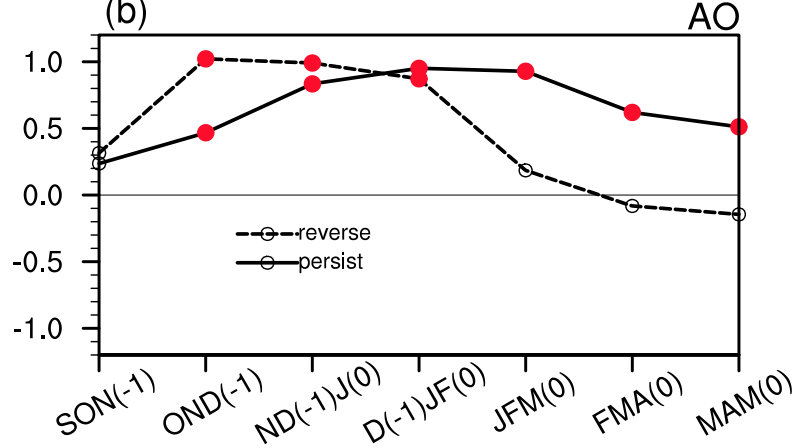

(c)

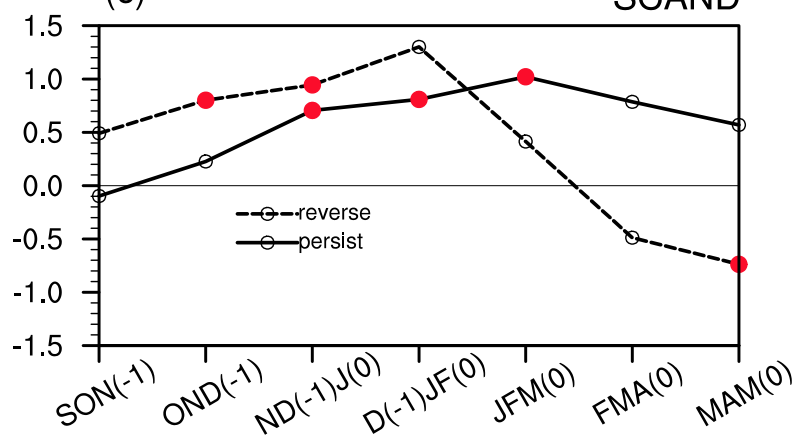

FIG. 6. Evolutions of composite anomalies of (a) SAT averaged over the mid- to high-latitude Eurasia $\left(40^{\circ}-70^{\circ} \mathrm{N}, 30^{\circ}-120^{\circ} \mathrm{E}\right)$, (b) the AO index, and (c) the SCAND index in the persistent cases (solid curves) and the reverse cases (dashed curves). Red dots indicate composite anomalies significant at the $95 \%$ confidence level.

closely related to atmospheric circulation anomalies. Then, a question to be addressed is why spring atmospheric circulation anomalies over Eurasia are similar (opposite) to those in the preceding winter in the persistent (reverse) cases. Given that the internal atmospheric processes cannot explain the persistence of atmospheric circulation anomaly patterns, the maintenance of atmospheric circulation anomalies may be attributed to the lower boundary forcing. In this section, we explore the role of the North Atlantic SST anomalies in the different evolutions of Eurasian atmospheric circulation anomalies. 

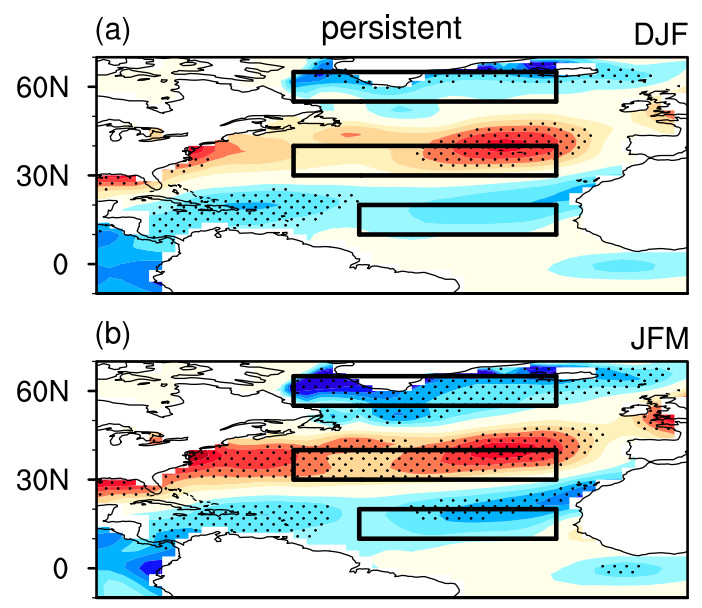

(c)

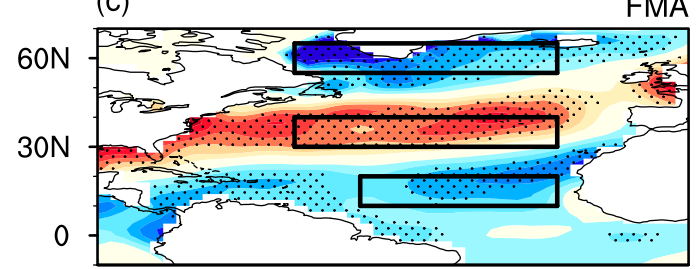

(d)

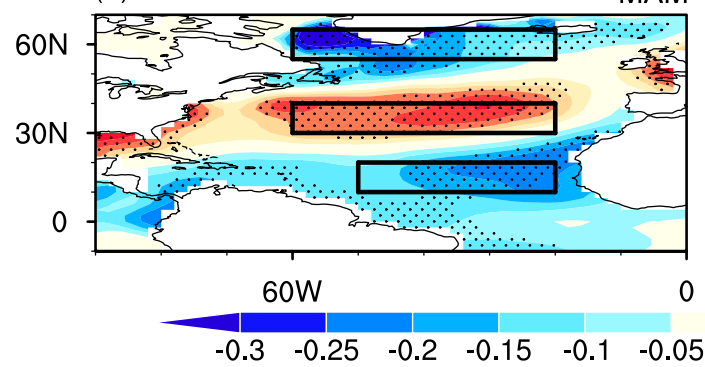

(e)

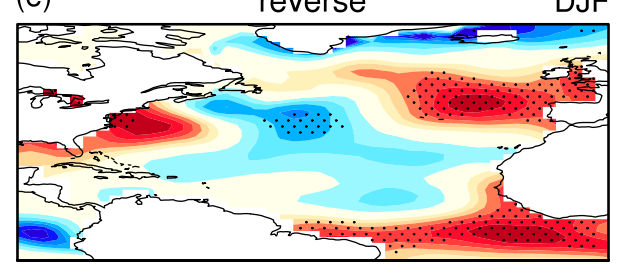

(f)

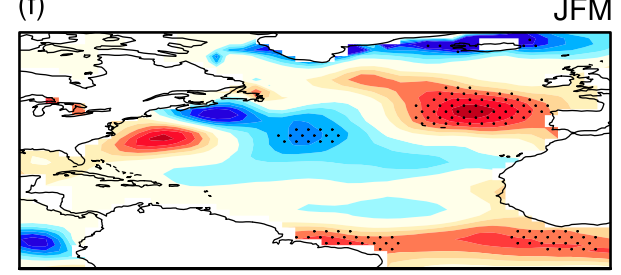

(g)

FMA

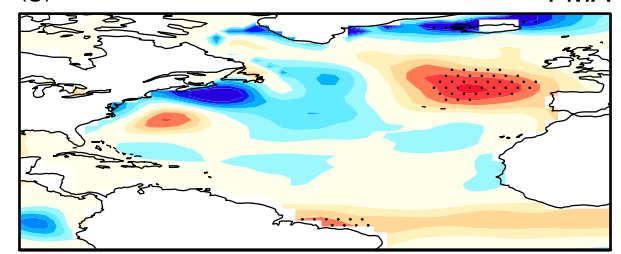

(h)

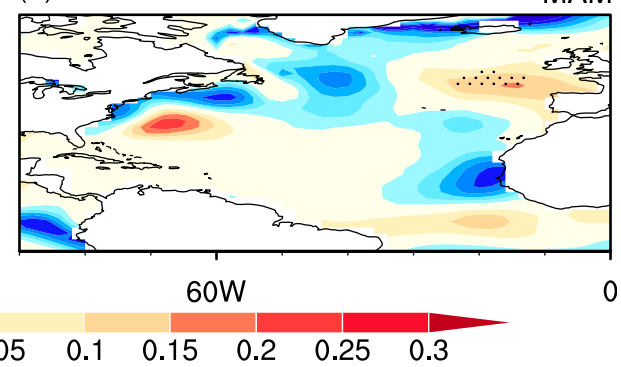

FIG. 7. Composite anomalies of SST $\left({ }^{\circ} \mathrm{C}\right)$ in (a),(e) DJF, (b),(f) JFM, (c),(g) FMA, and (d),(h) MAM for (left) the persistent cases and (right) the reverse cases. The stippled region indicates anomalies significant at the $95 \%$ confidence level. Black boxes are used to define the North Atlantic tripolar SST anomaly index as described in the text.

Very different spatial distribution and temporal evolution of the North Atlantic SST anomalies are identified in the two types of cases. In the persistent cases, a tripolar SST anomaly pattern is seen in the North Atlantic in winter, with warming in the midlatitudes and cooling in the tropics and high latitudes of the North Atlantic (Fig. 7a). The tripolar SST anomaly pattern maintains to the following spring with somewhat of an increase in the magnitude of SST anomalies (Figs. 7a-d). Note that the first EOF modes of winter and spring SST anomalies in the North Atlantic feature a tripolar pattern (not shown), similar to those shown in Figs. 7a-d. In the reverse cases, the distribution of SST anomalies in the North Atlantic differs from the tripole pattern. SST warming is seen in the equatorial Atlantic and off the west coast of Europe in winter (Fig. 7e). In addition, a small patch of SST cooling is seen around $35^{\circ} \mathrm{N}, 50^{\circ} \mathrm{W}$. The SST warming in the equatorial Atlantic decreases in the following months (Figs. 7f-h). The North Atlantic SST anomalies are weak and insignificant in spring (Fig. 7h).

The persisting negative SST anomalies in the tropical North Atlantic may contribute to the maintenance of anticyclonic wind and positive geopotential height anomalies over the subtropical North Atlantic (Figs. 3a-d and 4a-d) via a Rossby wave-type atmospheric response. The westerly wind anomalies to the northern flank of the anomalous anticyclone are accompanied by weakened storm track activity (not shown) as indicated by previous studies (Lau 1988; Cai et al. 2007; S. Chen et al. 2014; Chen et al. 2018b). The weakened storm track is immediately accompanied by cyclonic vorticity forcing to the north and anticyclonic vorticity forcing to the south (Lau 1988; Cai et al. 2007; S. Chen et al. 2014; Chen et al. 2018b), which explain the formation of the NAO-like atmospheric circulation 
anomaly pattern. Through the above processes, the North Atlantic SST anomalies contribute to NAO variability.

The evidence above indicates that the maintenance of the atmospheric circulation anomalies over the North Atlantic and Eurasia in the persistent cases may be due to the persisting SST anomaly pattern in the North Atlantic. Then, a question is what maintains the above SST anomaly pattern. This may be attributed to the interactions of the North Atlantic tripolar SST anomaly and the atmospheric circulation anomaly. A number of studies have demonstrated that there exists a positive interaction between the NAO-like atmospheric circulation anomaly and the North Atlantic tripolar SST anomaly pattern (Huang and Shukla 2005; Wu et al. 2009, 2010; Chen et al. 2016, 2018b; Zhao et al. 2019). On one hand, the NAO-related atmospheric anomalies induce the North Atlantic tripolar SST anomaly pattern via modulating surface heat fluxes (Czaja et al. 2002; Czaja and Frankignoul 2002; Huang and Shukla 2005; Pan 2005; Chen et al. 2016). The correlation between the NAO and North Atlantic tripolar SST anomaly pattern is strongest when the NAO leads the tripolar SST anomaly by about one month (Czaja and Frankignoul 2002). On the other hand, the North Atlantic SST anomalies have a feedback on the NAO-like atmospheric circulation anomalies via the wave-mean flow interaction (Czaja and Frankignoul 1999; Peng et al. 2003; Pan 2005), which plays an important role in maintaining the NAO-related atmospheric circulation.

Over the subtropical North Atlantic, northeasterly wind anomalies to the south flank of the anomalous anticyclone (Figs. 3a-d) increase surface wind speed and enhance upward latent heat flux (Figs. 8a-d), contributing to negative SST anomalies (Figs. 7a-d). Over the midlatitude North Atlantic, westerly wind anomalies around $60^{\circ} \mathrm{N}$ increase surface wind speed and increase upward latent heat flux, resulting in cooling as well. Over subtropical western North Atlantic, surface wind speed is reduced, suppressing upward latent heat flux and contributing to warming. The anticyclonic anomaly over the subtropical North Atlantic is accompanied by decrease in total cloud cover and increase in downward surface shortwave radiation (Figs. 8e-h). Over the lower latitudes, total cloud cover increases, reducing the shortwave radiation reaching the ocean surface. This indicates a negative contribution of the cloud-radiation effect on the warming in the subtropical North Atlantic and a positive contribution to the cooling in the tropical region. The magnitude of shortwave radiation anomalies is smaller compared to that of latent heat flux anomalies. The above interactions prolong the impact of the North Atlantic SST anomalies on the Eurasian atmospheric circulation and climate (Wu et al. 2009, 2010; Chen et al. 2018b).
To further confirm the close connection of the NAO with the North Atlantic tripolar SST anomaly, we examine 500-hPa geopotential height anomalies in winter and spring corresponding to the North Atlantic tripolar SST anomaly index. Here, we define a North Atlantic tripolar SST anomaly index using SST anomalies averaged over subtropical North Atlantic minus the sum of SST anomalies averaged over North Atlantic tropics and high latitudes (black boxes in Figs. 7a-d). A pronounced NAO-like meridional dipole atmospheric anomaly pattern is observed over the North Atlantic, and positive geopotential height anomalies are seen around Lake Baikal from winter to following spring in association with the positive North Atlantic tripolar SST index (Figs. 9a,b). We also examine the North Atlantic SST anomalies in winter and spring with regard to the respective normalized NAO index. A prominent tripolar SST anomaly pattern is found in the North Atlantic in winter and spring in association with the NAO index (Figs. 9c,d). The above analysis collectively suggests that the maintenance of the atmospheric circulation anomalies over the North Atlantic-Eurasian region in the persistent cases can be attributed to the air-sea interaction in the North Atlantic Ocean that maintains the North Atlantic tripolar SST anomaly pattern from winter to the following spring.

In the reverse cases, positive SST anomalies are observed in the equatorial Atlantic, the eastern part of the midlatitude North Atlantic, and the west coast of the subtropics in winter (Fig. 7e). Negative SST anomalies are seen in the central part of the subtropics and the high latitudes. These SST anomalies may contribute to the atmospheric circulation anomalies in winter. However, the North Atlantic SST anomalies are weak in spring (Fig. 7h). Due to the lack of the effects of the SST anomalies, the atmospheric anomalies over Eurasia in spring may be determined by the atmospheric internal processes and thus may differ from those in winter. The weak SST anomalies in spring may be related to the difference of the distribution of the winter North Atlantic SST anomalies from the tripolar pattern (Fig. 7e) and the difference of the distribution of winter wind anomalies from the NAO (Fig. 3e). Due to these differences, there is a lack of positive air-sea interaction between SST and atmospheric wind in the North Atlantic region. As such, the SST and atmospheric circulation anomalies cannot persist from winter to the following spring in the reverse cases.

\section{Role of the Arctic SIC anomalies}

As illustrated in the previous section, the air-sea interaction processes in the North Atlantic Ocean maintain the tripole SST anomaly pattern that provides a 

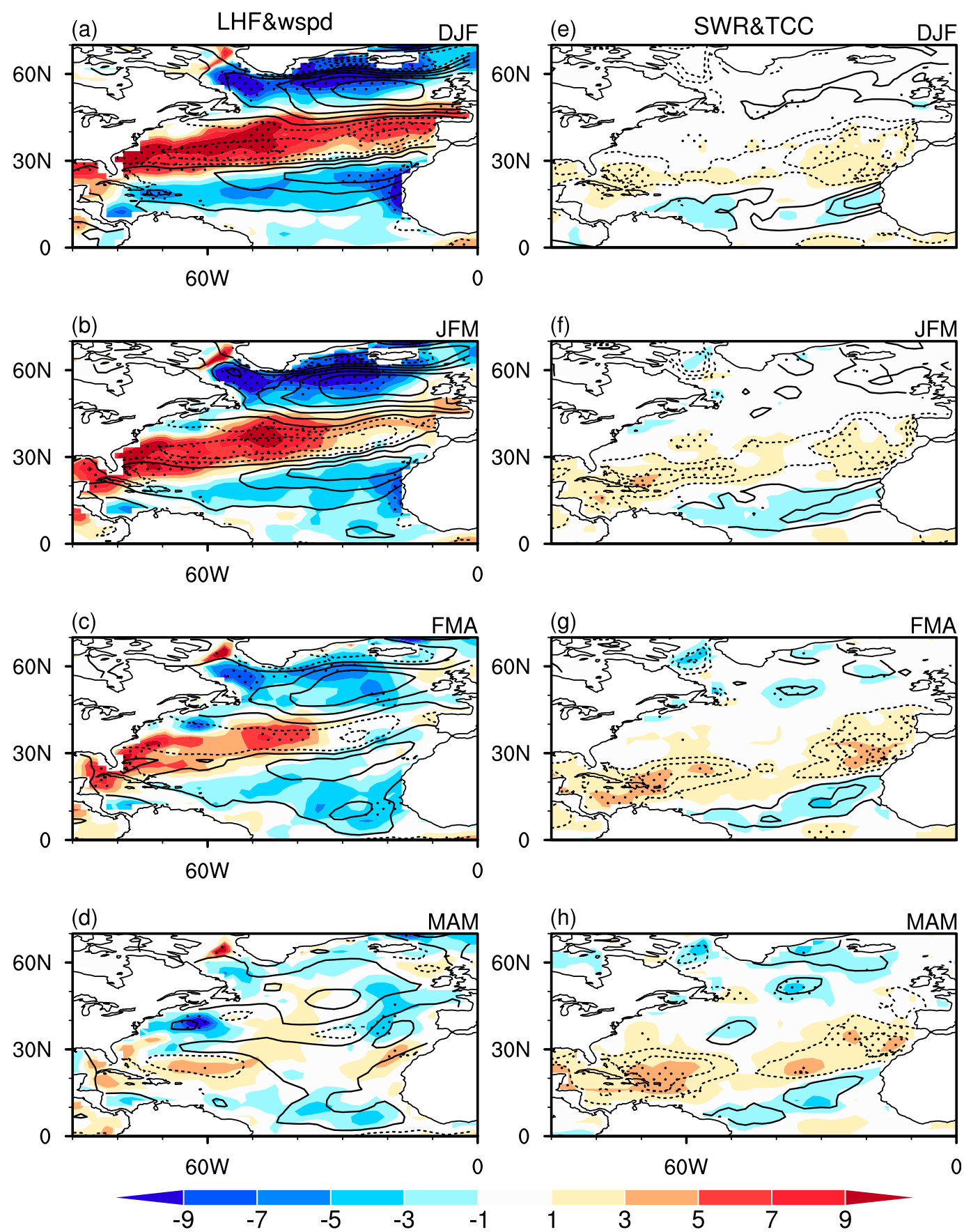

FIG. 8. Composite anomalies of surface latent heat flux (shadings; $\mathrm{W} \mathrm{m}^{-2}$ ) and surface wind speed (contours; $\mathrm{m} \mathrm{s}^{-1}$ ) in (a) DJF, (b) JFM, (c) FMA, and (d) MAM in the persistent cases. (e)-(h) As in (a)-(d), but for composite anomalies of surface net shortwave radiation (shadings; $\mathrm{W} \mathrm{m}^{-2}$ ) and total cloud cover (contours; \%). Stippled regions in (a)-(d) and (e)-(h) indicate anomalies of surface latent heat flux and net shortwave radiation, respectively, significant at the $95 \%$ confidence level. Here and in the following, positive values of surface heat flux indicate the direction is downward.

mechanism of the persistence of atmospheric circulation and SAT anomalies from winter to spring in the persistence cases. Are there any other factors that may play a role in the maintenance of the atmospheric circulation anomalies from winter to spring in the persistent cases? Recent studies indicated that Arctic SIC anomalies may exert a large impact on the atmospheric circulation and associated SAT anomalies over Eurasia (Wu et al. 2011; Li and Wu 2012; Liu et al. 2012; Vihma 2014; Nakamura et al. 2015; Gao et al. 2015; Wu et al. 2016; Chen and Wu 2018; Chen et al. 

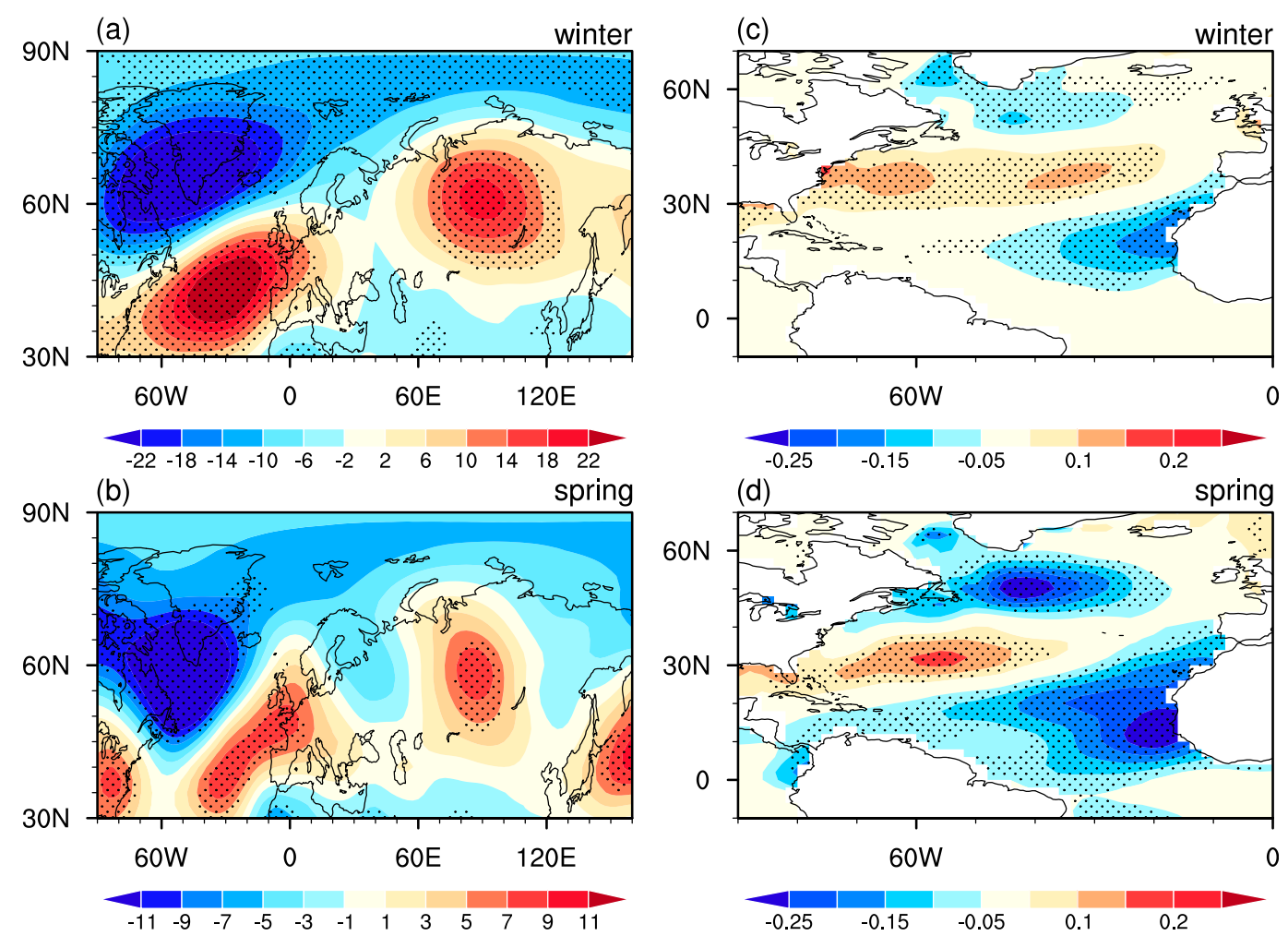

FIG. 9. The 500-hPa geopotential height anomalies (m) in (a) DJF and (b) MAM regressed upon the corresponding normalized North Atlantic tripolar SST anomaly index over 1949-2017. The definition of the North Atlantic tripolar SST anomaly index is provided in the text. Also shown are SST anomalies $\left({ }^{\circ} \mathrm{C}\right)$ in $(c)$ DJF and (d) MAM regressed upon the corresponding normalized NAO index over 1951-2017. The stippled region indicates anomalies significant at the $95 \%$ confidence level

2020). For example, Wu et al. (2016) reported that the maintained SIC anomalies around the Norwegian Sea and the Barents Sea from winter to following spring could exert an impact on the spring Eurasian climate via inducing atmospheric wave train. In this section, we explore the role of the Arctic SIC anomalies.

In the persistent cases, SIC decrease is seen around the Barents Sea from the preceding fall to subsequent spring with an increase in the magnitude of SIC anomalies (Figs. 10a-f). Note that spatial distributions of SIC anomalies in Figs. 10a-f are generally similar to the spatial patterns of the first EOF modes of SIC anomalies in the corresponding seasons (not shown). Does the SIC decrease in the Barents Sea region contribute to the maintenance of the atmospheric circulation anomalies over the North Atlantic and Eurasia? To address this issue, we examine surface heat flux anomalies in the Barents Sea region that may provide information whether the sea ice change affects the local atmosphere. For example, sea ice decrease may enhance upward sensible heat flux and longwave radiation. On the other hand, atmospheric process-induced surface air temperature may affect the sea ice formation and melting.
In winter, the SIC decrease in the Barents Sea is accompanied by SAT increase (Figs. 11a,b). Surface sensible heat flux anomalies are negative in the sea icecovered region, indicative of the sea ice effect (Fig. 11d). This sensible heat flux decrease region, however, is small. Positive sensible heat flux anomalies are seen in a larger region off the coast of northern Europe, which is likely due to the SAT increase that reduces the sea-air temperature difference as surface wind speed anomalies are small there (Fig. 11c). The SAT increase is likely due to anomalous southerly winds (Fig. 3a) that bring warmer and wetter air from lower latitudes. The wetter air also favors the increase in cloud cover (Fig. 11e), which, together with the warmer air, enhances downward longwave radiation (Fig. 11f) that contributes to the SST increase (Fig. 11h). The upward longwave radiation increase (Fig. 11g) is attributed to the sea ice decrease. The magnitude of upward and downward longwave radiation anomalies is comparable $\left(-4.8\right.$ and $\left.+4.5 \mathrm{~W} \mathrm{~m}^{-2}\right)$, leading to a small net effect (Table 2). Overall, the above surface heat flux anomalies suggest that the sea ice change is more likely a result of the SAT and SST increase and has a limited effect on the SAT change. 

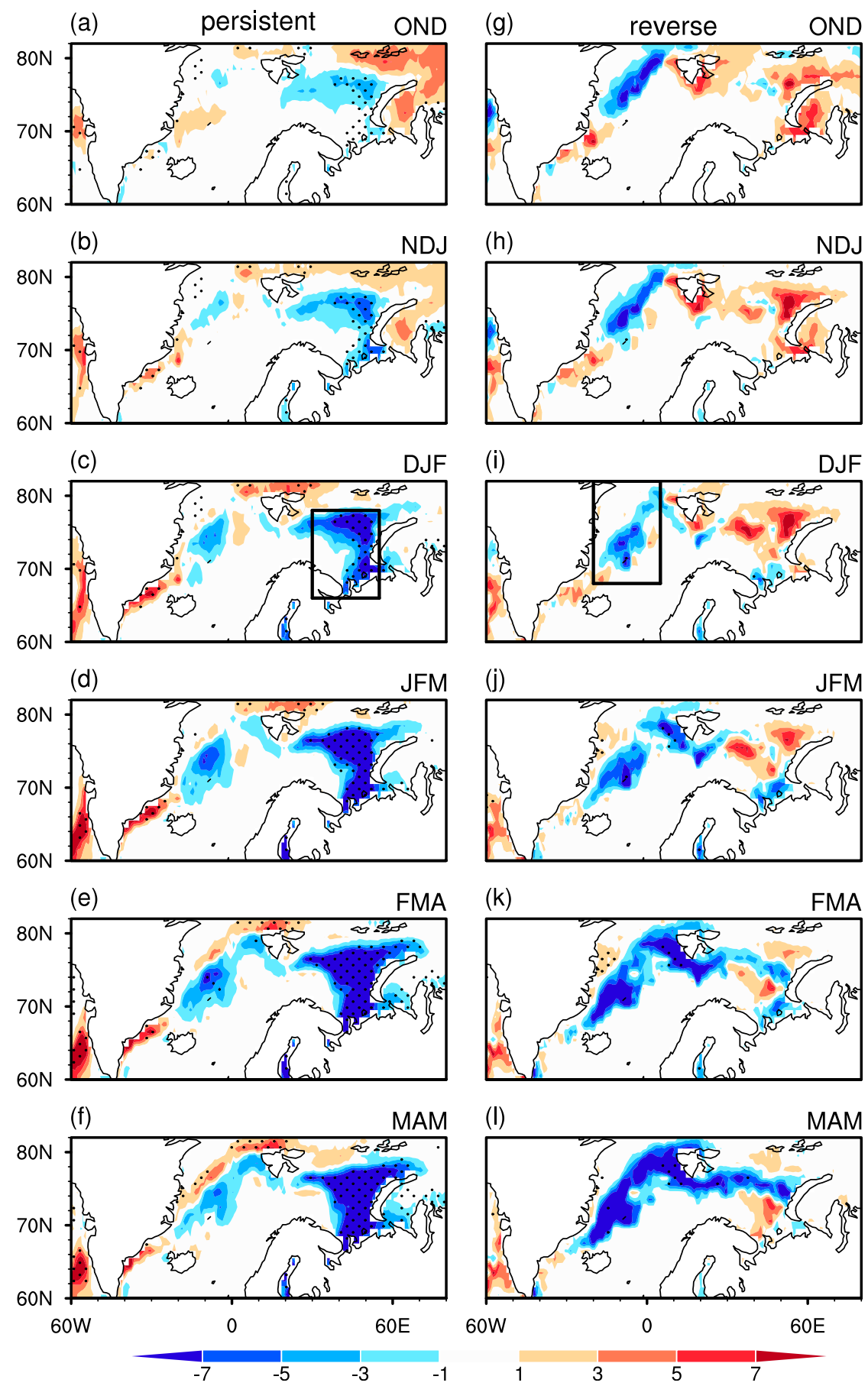

FIG. 10. Composite anomalies of Arctic sea ice concentration (SIC) (\%) in (a),(g) OND, (b),(h) NDJ, (c),(i) DJF, (d),(j) JFM, (e),(k) FMA, and (f),(l) MAM for (left) the persistent cases and (right) the reverse cases. Stippling region indicates anomalies significant at the $95 \%$ confidence level. The black box in (c) is used to define the Barents Sea SIC index.

In spring, SIC decrease and SAT increase are observed in the Barents Sea region as well (Figs. 12a,b). Different from DJF, negative sensible heat flux anomalies $\left(-1.8 \mathrm{~W} \mathrm{~m}^{-2}\right.$; Table 2$)$ are seen over most of the
Barents Sea (Fig. 12d), indicative of the sea ice effect with little wind speed effect (Fig. 12c). The total cloud cover increases (Fig. 12e), which contributes to the increase in downward longwave radiation (Fig. 12h) and 
TABLE 2. Composite anomalies $\left(\mathrm{W} \mathrm{m}^{-2}\right)$ of surface sensible heat flux (SHF), latent heat flux (LHF), downward longwave radiation (dLWR), upward longwave radiation (uLWR), downward shortwave radiation (dSWR), and upward shortwave radiation (USWR) in winter and spring averaged over the domain of $66^{\circ}-78^{\circ} \mathrm{N}$ and $30^{\circ}-55^{\circ} \mathrm{E}$ (i.e., the black box in Fig. 10c).

\begin{tabular}{lrrcccc}
\hline & SHF & LHF & dLWR & uLWR & dSWR & uSWR \\
\hline Winter & 1.9 & -0.2 & 4.5 & -4.8 & -0.05 & 0.13 \\
Spring & -1.8 & -1.9 & 3.2 & -3.9 & -2.1 & 5.0 \\
\hline
\end{tabular}

the decrease in downward shortwave radiation (Fig. 12f). Another effect of SIC decrease is the increase in upward longwave radiation (Fig. 12i) and the reduction in upward shortwave radiation (Fig. 12g). The upward shortwave radiation reduction $\left(+5.0 \mathrm{~W} \mathrm{~m}^{-2}\right)$ is larger than the downward shortwave radiation decrease $\left(-2.1 \mathrm{~W} \mathrm{~m}^{-2}\right)$, contributing to the SST increase (Fig. 12j). Another difference from DJF is that the upward longwave radiation anomalies $\left(-3.9 \mathrm{~W} \mathrm{~m}^{-2}\right)$ are larger than the downward longwave radiation anomalies $\left(+3.2 \mathrm{~W} \mathrm{~m}^{-2}\right)$, leading to a net effect on the air temperature increase (Table 2). This, together with upward sensible heat flux, confirms the impact of the sea ice decrease on the atmosphere in spring by modulating the thermal status of lower troposphere.

The above analysis indicates that the sea ice anomalies in the Barents Sea region may form due to the atmospheric change in winter and in turn may contribute to the maintenance of the atmospheric circulation anomalies in spring. To confirm the sea ice impact on atmospheric circulation anomalies, we examine 500-hPa geopotential height anomalies from DJF to following MAM with respect to a Barents Sea SIC index defined by averaging winter SIC anomalies over $66^{\circ}-78^{\circ} \mathrm{N}, 30^{\circ}-55^{\circ} \mathrm{E}$ (black box in Fig. 10c). Corresponding to negative Barents Sea SIC index, a positive NAO-like atmospheric circulation anomaly pattern over the North Atlantic and positive geopotential height anomalies northwest of the Lake Baikal are maintained from winter to following spring (Fig. 13). These geopotential height anomalies bear resemblances to those in Figs. 4a-d. This implies that the SIC anomalies in the Barents Sea may also partly contribute to the maintenance of atmospheric circulation anomalies over the North Atlantic and Eurasia. There have been many studies that indicate the impacts of autumn-winter Barents Sea ice change on winter and spring Eurasian circulation and temperature anomalies (Honda et al. 2009; Wu et al. 2011; Liu et al. 2012; Li and Wang 2013; Z. Chen et al. 2014; Gao et al. 2015; Sun et al. 2016; Wu et al. 2016; Chen and Wu 2018; Li et al. 2019). The detailed physical processes for the impact of the Barents Sea SIC anomalies on the maintenance of Eurasian atmospheric circulation remain to be explored.
We have examined surface heat flux anomalies in the Greenland Sea region (i.e., $68^{\circ}-82^{\circ} \mathrm{N}, 20^{\circ} \mathrm{W}-5^{\circ} \mathrm{E}$ ) to identify whether the sea ice change affects local atmosphere in the reverse cases. In winter, the SIC and SAT anomalies are insignificant in this region (figures not shown). In spring, large positive sensible heat flux anomalies $\left(+5.3 \mathrm{~W} \mathrm{~m}^{-2}\right)$ are observed to the south side of the sea ice-covered region, indicative of the effect of SAT increase and wind speed decrease. The downward longwave radiation anomalies $\left(+8.7 \mathrm{~W} \mathrm{~m}^{-2}\right)$ exceed the upward longwave radiation anomalies $\left(-6.1 \mathrm{~W} \mathrm{~m}^{-2}\right)$. The above features suggest that the sea ice change has no obvious effect on the air temperature change. Another plausible factor that may contribute to the atmospheric circulation is snow cover. Previous studies indicate the impacts of the snow cover on Eurasian winter and spring SAT anomalies (Cohen and Fletcher 2007; Cohen et al. 2012; Chen et al. 2016; Wu and Chen 2016). We have examined the winter and spring Eurasian snow cover anomalies in the persistent cases to inspect the role of snow. In winter, the snow cover decrease is limited to southern Europe (Fig. 14a) where SAT anomalies are relatively small (Fig. 2a). The sensible heat flux anomalies are positive in the region (Fig. 14c), which indicates that SAT change may dominate the sensible heat flux. In spring, snow cover anomalies extend eastward along the midlatitudes (Fig. 14b). The sensible heat flux anomalies, however, are small and positive south of $60^{\circ} \mathrm{N}$ (Fig. 14d). Again, this indicates that the control of SAT change and snow cover has little effect on the atmosphere.

\section{Summary and discussion}

This study investigates the evolution of SAT anomalies over the mid- to high latitudes of Eurasia from winter to following spring based on reanalysis and observational data over 1949-2017. The dominant modes of both winter and spring SAT interannual variations display continental-scale SAT warming/cooling over mid- to high-latitude Eurasia. The PC time series corresponding to EOF1 of winter and spring Eurasian SAT display a positive correlation coefficient of about 0.29 . This indicates that large-scale SAT warming/cooling over Eurasia in winter tends to be maintained to following spring. In addition, there exist a number of years when winter SAT anomalies are opposite to those in the following spring. We compare the temporal evolution of atmospheric circulation, SST, sea ice, and snow cover anomalies in the two different types (i.e., the persistent cases and the reverse cases) to understand the reasons for persistence of continental SAT anomalies from winter to spring. The results are summarized in Fig. 15. 
(a)

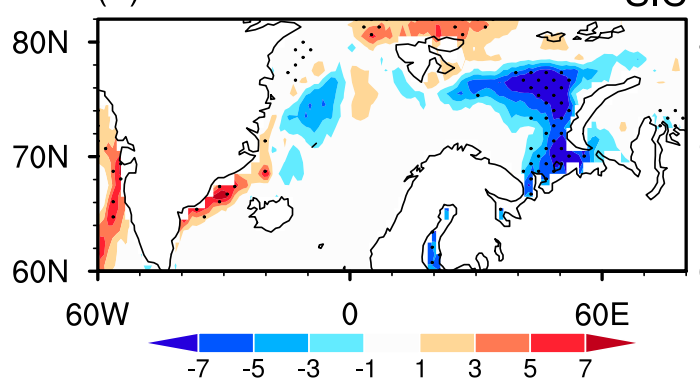

(c)

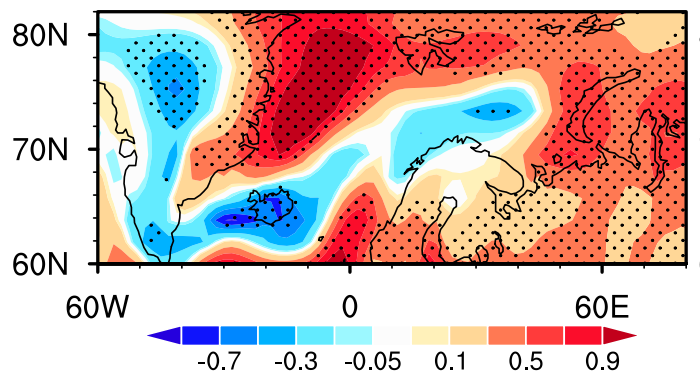

(e)

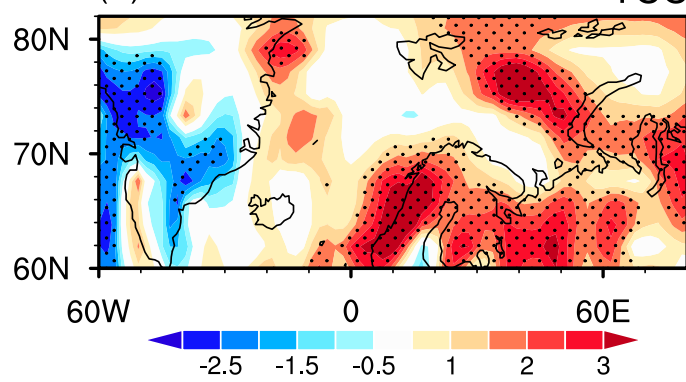

(g)

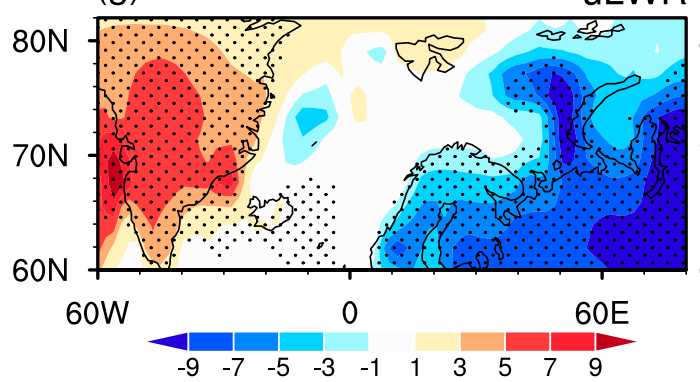

(b)

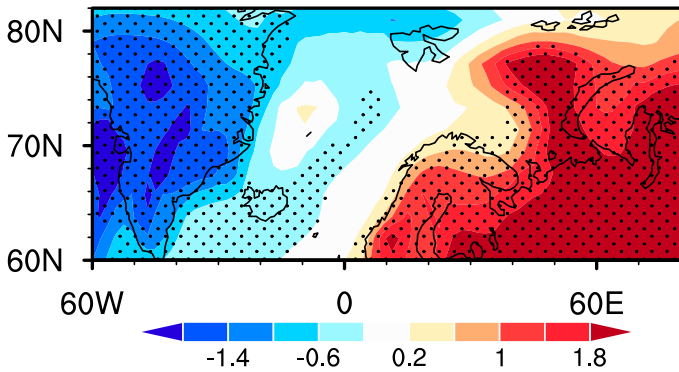

(d)

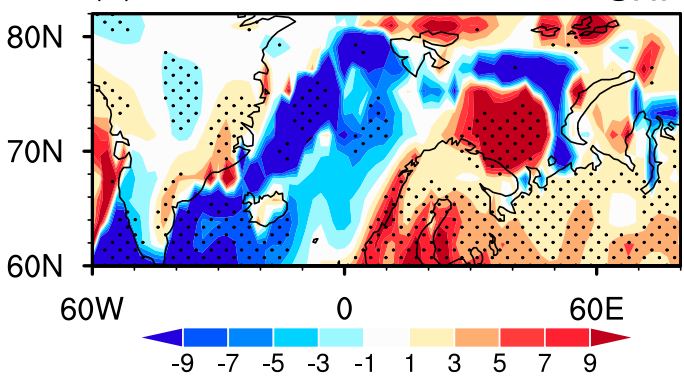

(f)

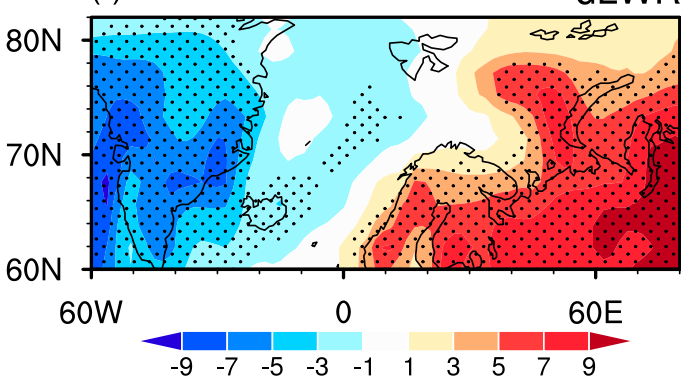

(h)

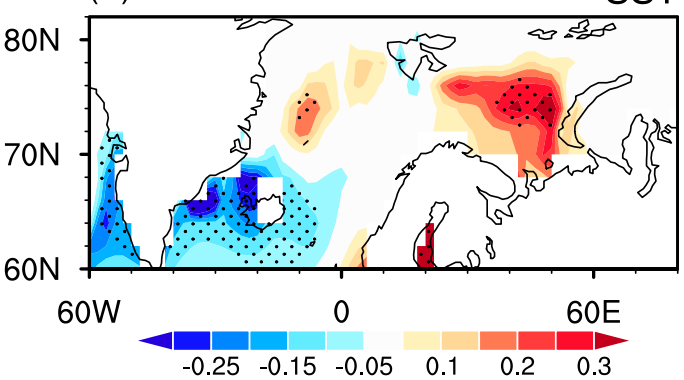

FIG. 11. Composite anomalies of (a) SIC (\%), (b) SAT $\left({ }^{\circ} \mathrm{C}\right)$, (c) surface wind speed $\left(\mathrm{m} \mathrm{s}^{-1}\right)$, (d) surface sensible heat flux $\left(\mathrm{W} \mathrm{m}^{-2}\right),(\mathrm{e})$ total cloud cover $(\%)$, (f) surface downward longwave radiation $\left(\mathrm{W} \mathrm{m}^{-2}\right)$, (g) surface upward longwave radiation $\left(\mathrm{W} \mathrm{m}^{-2}\right)$, and $(\mathrm{h}) \mathrm{SST}\left({ }^{\circ} \mathrm{C}\right)$ in DJF in the persistent cases. Stippled regions indicate anomalies significant at the $95 \%$ confidence level.

In the persistent cases, pronounced SAT warmings over the mid- to high latitudes of Eurasia in winter can be sustained to the following spring (Figs. 15a,b). This is attributed to the maintenance of the associated atmospheric circulation anomalies over the North Atlantic and Eurasia (Figs. 15a,b). The winter atmospheric circulation anomalies in the persistent cases bear some resemblances to those related to the NAO/AO and SCAND pattern. Anticyclonic wind and positive geopotential height anomalies are present over subtropical 
(a)

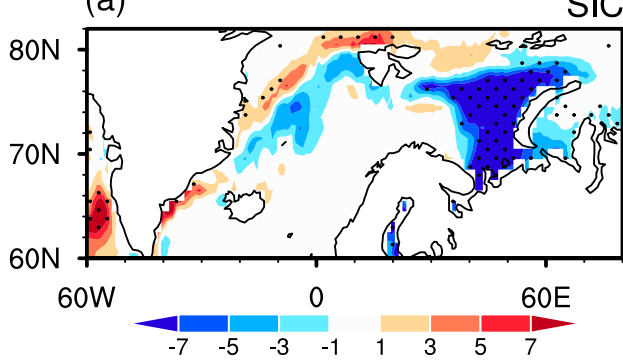

(c)

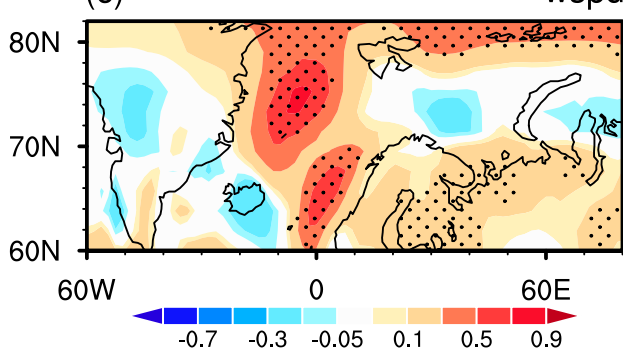

(e)

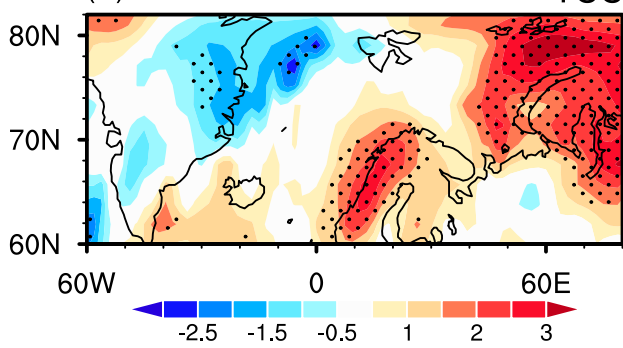

(g)

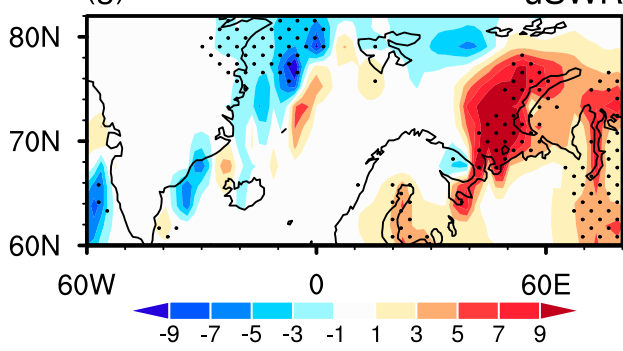

(i)

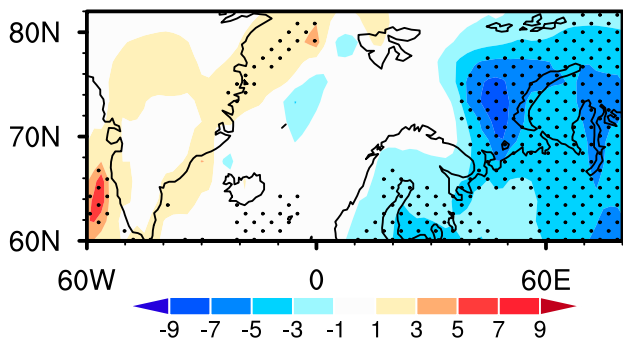

TCC (b)

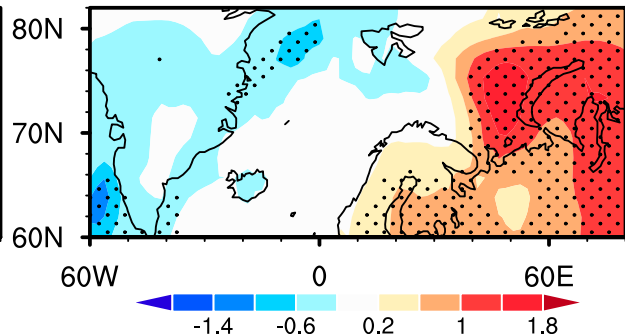

(d)

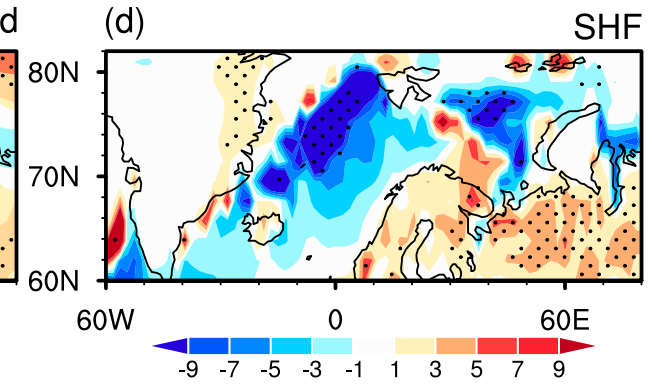

SHF

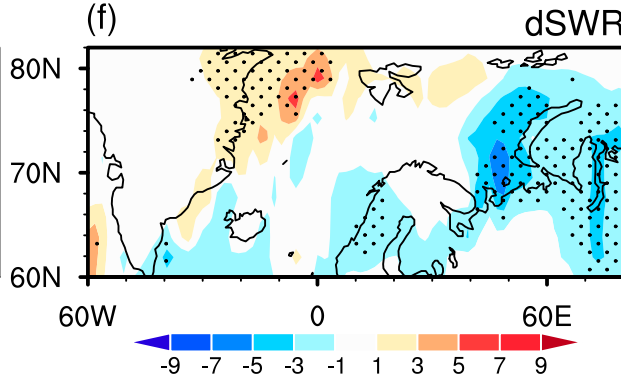

dSWR
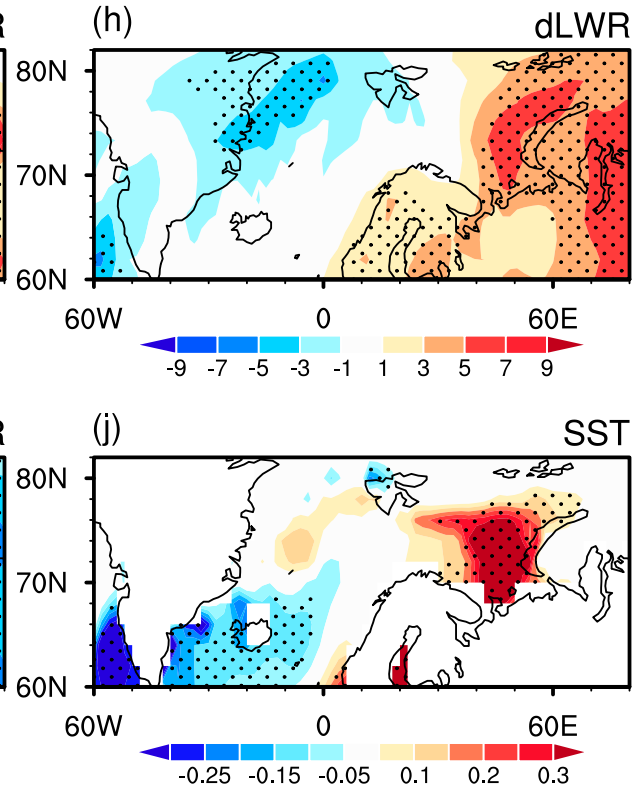

FIG. 12. Composite anomalies of (a) SIC $(\%)$, (b) SAT $\left({ }^{\circ} \mathrm{C}\right)$, (c) surface wind speed $\left(\mathrm{m} \mathrm{s}^{-1}\right)$, (d) surface sensible heat flux $\left(\mathrm{W} \mathrm{m}^{-2}\right)$, (e) total cloud cover (\%), (f) surface downward shortwave radiation $\left(\mathrm{W} \mathrm{m}^{-2}\right)$, (g) surface upward shortwave radiation $\left(\mathrm{W} \mathrm{m}^{-2}\right)$, (h) surface downward longwave radiation $\left(\mathrm{W} \mathrm{m}^{-2}\right)$, (i) surface upward longwave radiation $\left(\mathrm{W} \mathrm{m}^{-2}\right)$, and (j) SST $\left({ }^{\circ} \mathrm{C}\right)$ in MAM in the persistent cases. Anomalies significant at the $95 \%$ confidence level are stippled. 
(a)

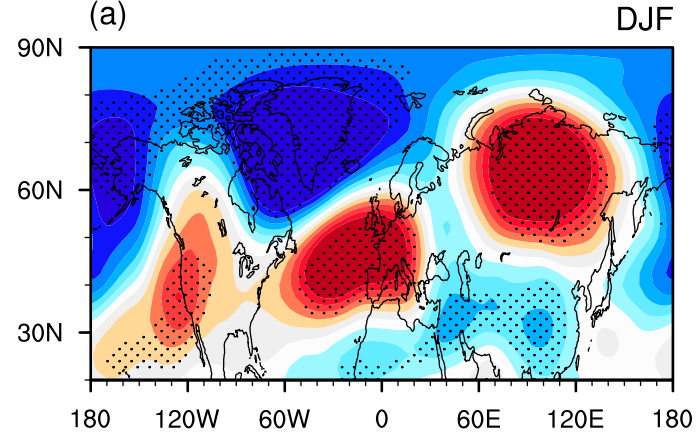

(c)

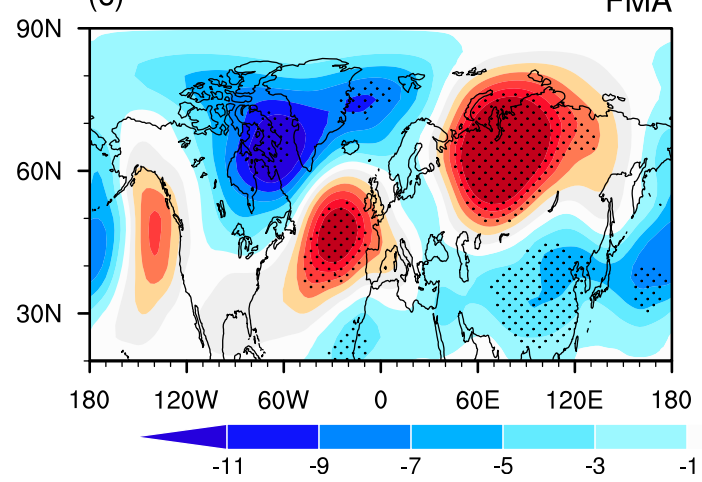

(b)

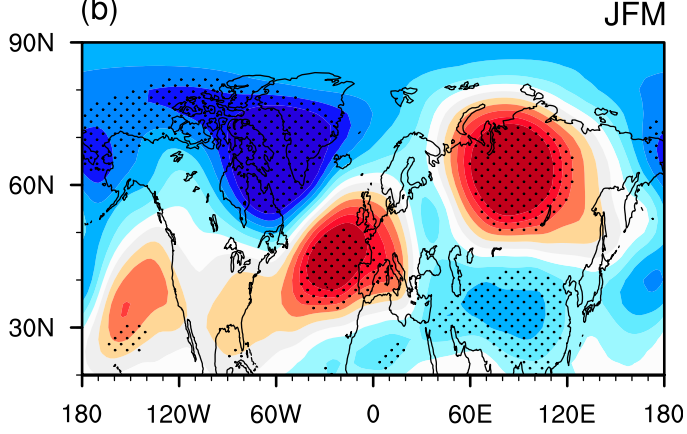

(d)

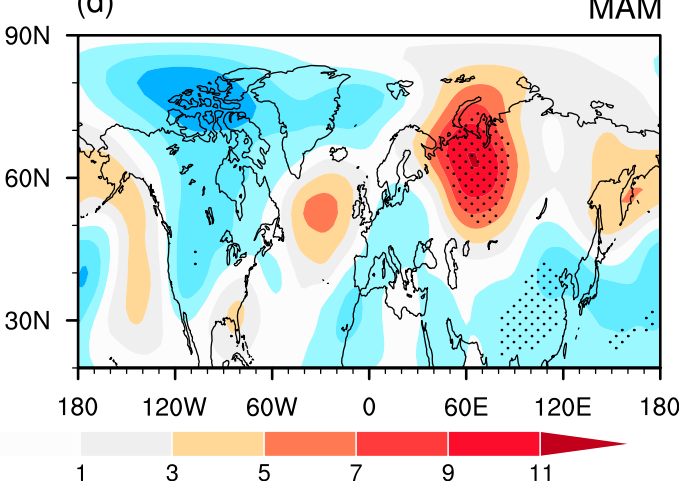

FIG. 13. The 500-hPa geopotential height anomalies (m) in (a) DJF, (b) JFM, (c) FMA, and (d) MAM obtained by regression onto the reverted normalized winter SIC index defined by averaging SIC anomalies over the region $66^{\circ}-78^{\circ} \mathrm{N}, 30^{\circ}-55^{\circ} \mathrm{E}$. The stippled region indicates anomalies significant at the $95 \%$ confidence level.

North Atlantic and central Eurasia, and negative geopotential height and cyclonic wind anomalies are observed over the high-latitude North Atlantic and the Eurasian part of the Arctic (Fig. 15a). The associated westerly/southwesterly wind anomalies bring warmer and moister air from the North Atlantic and lower latitudes and lead to SAT warming over most parts of Eurasia. The above winter atmospheric circulation anomaly pattern can maintain to following spring, accounting for the persistence of SAT warming from winter to following spring (Fig. 15b).

The maintenance of the atmospheric circulation anomalies over the North Atlantic and Eurasia is attributed to the North Atlantic tripole-like SST anomaly pattern as well as partly to the SIC anomalies in the Barents Sea (Figs. 15a,b). The North Atlantic tripole SST anomaly pattern maintains from winter to spring via air-sea interaction processes in which the wind-related surface latent heat flux is a dominant factor in the persistent SST anomalies. The SIC anomalies in the Barents Sea region form in winter due to atmospheric changes and maintain to spring and then contribute to the atmospheric circulation anomalies via modulating the thermal status of lower troposphere. Notable snow cover anomalies are identified over Europe in winter and extend eastward over the midlatitude in spring due to atmospheric changes.

In the reverse cases, notable SAT warmings in winter over the mid- to high latitudes of Eurasia are accompanied by pronounced SAT coolings in the following spring with comparable amplitude (Figs. 15c,d). The winter atmospheric circulation anomalies in the reverse cases bear a closer resemblance to those related to the winter SCAND pattern. Negative geopotential height anomalies extend eastward from Greenland to the Barents Sea, and pronounced positive geopotential height anomalies are present around west Europe and the Lake Baikal (Fig. 15c). The associated wind anomalies contribute to SAT warming over Eurasia via anomalous wind-induced horizontal temperature advection (Fig. 15c). In the following spring, negative geopotential height anomalies over the North Atlantic and Eurasian parts of the Arctic are replaced by positive geopotential height anomalies (Fig. 15d). Mid- to high-latitude Eurasia is dominated by notable negative geopotential height anomalies. As such, the atmospheric circulation anomaly pattern in spring is almost opposite to that in the preceding winter. Hence, opposite-signed SAT anomalies occur over Eurasia in winter and spring due to the reversed atmospheric circulation anomalies (Figs. 15c,d). 

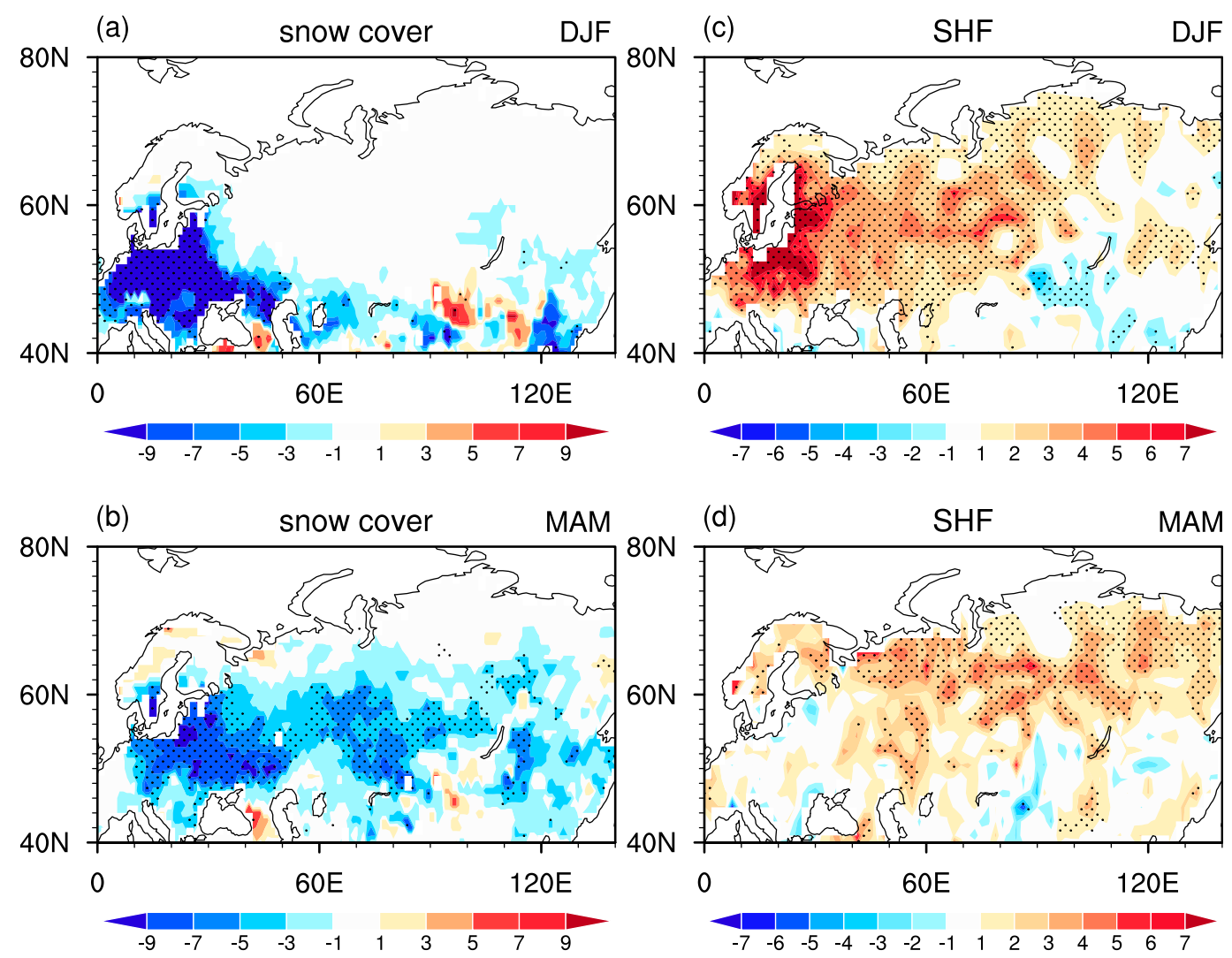

FIG. 14. Composite anomalies of (left) snow cover extent (\%) and (right) surface sensible heat flux ( $\left.\mathrm{W} \mathrm{m}^{-2}\right)$ in (a),(c) DJF and (b),(d) MAM in the persistent cases. Stippled regions indicate anomalies significant at the $95 \%$ confidence level.

The North Atlantic SST anomalies play a role in the atmospheric circulation anomalies over the North Atlantic and Eurasia in winter in the reverse cases. The SST anomalies, however, become small in spring. Notable Arctic SIC changes are observed in the Greenland Sea in spring (Figs. 15c,d), but they are likely responses to the atmospheric change and have no obvious impacts on the atmosphere. Due to the lack of lower boundary forcing, the switch of the atmospheric circulation anomaly pattern from winter to spring is likely due to the internal atmospheric processes in the reverse cases.

As both the NAO/AO and Barents Sea ice contribute to the Eurasian SAT anomalies, one may ask whether there is a connection between the NAO/AO and Barents Sea ice variations and what the relative contributions are of the NAO/AO and Barents Sea ice anomalies. The correlation coefficient between the winter AO (North Atlantic SST tripolar index) and the winter Barents Sea ice index is $-0.21(-0.04)$ during 1948-2018, which is fairly weak. For the 22 persistent years (Table 1 ), the correlation coefficient of the winter Barents Sea ice index with the winter $\mathrm{AO}$ and North Atlantic tripolar SST indices are about -0.34 and -0.35 , respectively, still below the $95 \%$ confidence level. This indicates a weak connection of the SIC anomalies around the Barents Sea with the AO and North Atlantic tripolar SST anomaly pattern. For the 22 persistent years, the correlation coefficient between the winter $\mathrm{AO}$ index (winter SIC index) with the PC1 time series of spring SAT anomalies over mid- to high-latitude Eurasia is about $0.74(-0.54)$. This suggests that the contribution of the preceding winter AO to the interannual variation of spring SAT over mid- to high-latitude Eurasia is larger than that of the winter Barents Sea ice changes.

We further establish an empirical model to predict persistence of the EOF1 based on the winter North Atlantic SST tripolar anomaly pattern and the winter SIC anomalies around the Barents Sea for the persistent cases (a total of 22 years). Here, persistence of the EOF1 of SAT is represented by the average of PC1 of SAT anomalies in winter and spring (i.e., Figs. 1c,d). The empirical model is expressed as follows: 

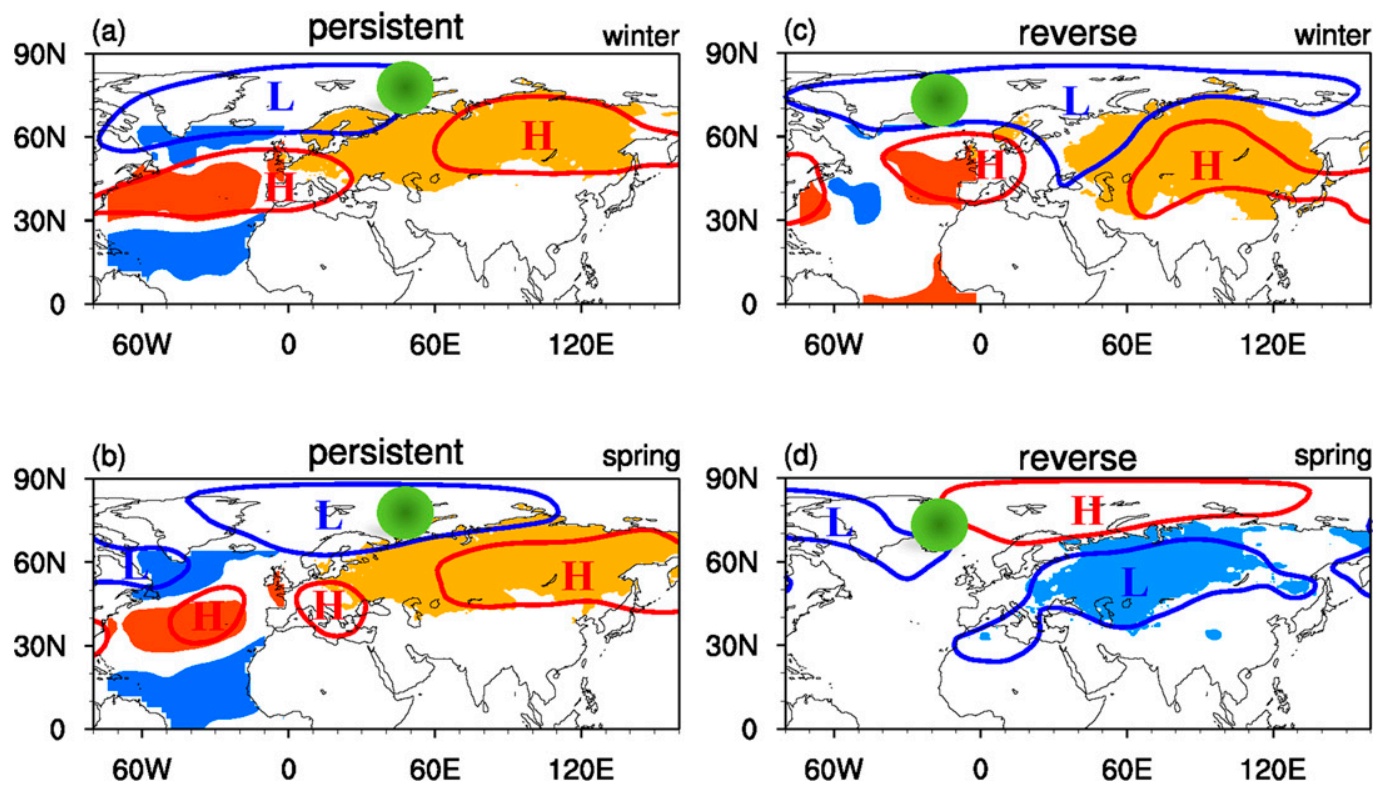

FIG. 15. Schematic diagram showing different evolutions of SAT, 500-hPa geopotential height, SST, and Arctic SIC anomalies for (left) the persistent cases and (right) the reverse cases. Red and blue contours represent 500-hPa geopotential height anomalies. Yellow (blue) shadings over the Eurasian continent represent above-normal (below-normal) SAT. Brown (blue) shadings in the North Atlantic represent SST warming (cooling). Green shadings over Arctic denote below-normal SIC anomalies.

Persist_EOF $(t)=a \times \operatorname{NATSST}(t)+b \times \operatorname{SIC}(t)$,

where $t$ denotes the time of year, Persist_EOF represents the persistence of the EOF1, NATSST denotes the North Atlantic tripolar SST anomaly index in winter, and SIC denotes winter SIC anomalies averaged over the domain $66^{\circ}-78^{\circ} \mathrm{N}, 33^{\circ}-55^{\circ} \mathrm{E}$ (i.e., the black box in Fig. 10c). Following previous studies (Ham et al. 2013; Chen et al. 2018b), the ability of the empirical model is cross-validated via employing the leave-one-out method (excluding one year from the persistent years, calculating the regression coefficient of the linear regression model via the remaining years, and hindcasting the value of the excluded year). The cross-validated correlation reaches $0.63(0.50)$ when the winter North Atlantic SST index (SIC index) is used to hindcast the persistent EOF1 (Fig. 16). If both the winter North Atlantic SST index and SIC index are used to hindcast the persistent EOF1, the cross-validated correlation is 0.73 , which is higher than that using only winter North Atlantic SST index or SIC index to predict the persistent EOF1 (Fig. 16). This implies that the winter North Atlantic SST and Arctic SIC anomalies indeed both provide sources for the prediction of the persistence of Eurasian SAT.

Results in this study highlight the important roles of the North Atlantic SST and Arctic SIC changes in sustaining the large-scale atmospheric circulation anomaly pattern and in the maintenance of SAT anomalies over the mid- to high latitudes of Eurasia from winter to following spring. These results have important implications for the seasonal predictions of mid- to high-latitude Eurasian SAT anomalies.

In the present study, the maintenance of the North Atlantic SST anomalies are attributed to the air-sea

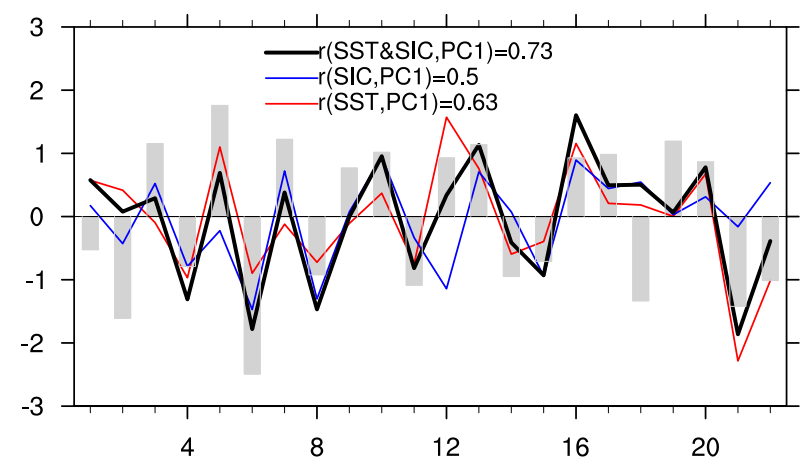

FIG. 16. Time series of the persistent EOF1 (represented by the average of PC1 time series of the winter and spring Eurasian SAT anomalies) for the selected persistent cases (a total of 22 years as shown in Table 1) (gray bars), and the cross-validated hindcasts of the persistent EOF1 calculated by the empirical model using the winter North Atlantic tripolar SST index alone (red line), using the winter SIC index alone (blue line), and using both the winter North Atlantic tripolar SST index and winter SIC index (black line). The correlation coefficients between various time series are also provided in the figure. 
interaction processes within the North Atlantic region. Previous studies showed that the Pacific El Niño-Southern Oscillation (ENSO) may contribute to the North Atlantic SST variations and atmospheric circulation anomalies via atmospheric teleconnection (Klein et al. 1999; Saravanan and Chang 2000; Alexander et al. 2002; Czaja et al. 2002; Wu and Zhang 2015; Zhang et al. 2019a,b). It remains to be investigated whether there is a role of the ENSO events in the maintenance of the tripole SST anomaly pattern in the North Atlantic Ocean and whether the role of the ENSO events depends upon the location and temporal evolution of ENSO-related SST anomalies in the tropical Pacific Ocean.

Studies indicated that Eurasian SAT and atmospheric circulation anomalies are also impacted by the stratospheric polar vortex via downward propagation process (Gu and Yang 2006; Wei et al. 2011; Lu and Ding 2015; Li et al. 2017). In addition, studies indicated that the NAO/ $\mathrm{AO}$ is tightly coupled with the stratospheric polar vortex (Baldwin and Dunkerton 1999; Ambaum and Hoskins 2002; Baldwin et al. 2003). Indeed, we identify negative geopotential height anomalies at $50 \mathrm{hPa}$ over the Arctic (indicating a strengthened polar vortex) from winter to spring for the persistent cases (not shown). This implies that the stratospheric polar vortex may also be important for the persistence of atmospheric circulation and SAT anomalies over the mid- to high latitudes of Eurasia. The detailed processes for the contribution of the stratospheric polar vortex to the maintenance of the Eurasian SAT anomalies from winter to spring remain to be explored.

From Table 1, there are more persistent cases in the 1960s, 1980s, and 2000s, but more reverse cases in the 1950s. This indicates an interdecadal change in the frequency of occurrence of persistent and reverse cases. A sliding correlation analysis shows that the winter-spring $\mathrm{PC} 1$ s have a significant positive correlation during the 1960s and 1970s and the correlation becomes weak during 1980s through 2000s. It remains to be explored what led to such interdecadal changes.

Acknowledgments. We thank two anonymous reviewers for their constructive suggestions, which helped to improve the paper. This study is supported by the National Natural Science Foundation of China grants (41530425, 41775080, and 41605050) and the Young Elite Scientists Sponsorship Program by the China Association for Science and Technology (2016QNRC001). The University of Delaware Air Temperature and Precipitation version v5.01 dataset is obtained from https://www.esrl.noaa.gov/psd/ data/gridded/data.UDel_AirT_Precip.html. NCEP-NCAR reanalysis data are derived from ftp://ftp.cdc.noaa.gov. ERSSTv3b and ERSSTv5 SST data are obtained from https:// www.esrl.noaa.gov/psd/data/gridded/. The teleconnection indices are extracted from https://www.cpc.ncep.noaa.gov/ data/teledoc/telecontents.shtml. The SCE data are obtained from $\mathrm{ftp} / / /$ sidads.colorado.edu/pub/DATASETS.

\section{REFERENCES}

Alexander, M. A., I. Bladé, M. Newman, J. R. Lanzante, N.-C. Lau, and J. D. Scott, 2002: The atmospheric bridge: The influence of ENSO teleconnections on air-sea interaction over the global oceans. J. Climate, 15, 2205-2231, https://doi.org/10.1175/15200442(2002)015<2205:TABTIO > 2.0.CO;2.

Ambaum, M. H. P., and B. J. Hoskins, 2002: The NAO tropospherestratosphere connection. J. Climate, 15, 1969-1978, https:// doi.org/10.1175/1520-0442(2002)015<1969:TNTSC >2.0.CO;2.

Baldwin, M. P., and T. J. Dunkerton, 1999: Propagation of the Arctic Oscillation from the stratosphere to the troposphere. J. Geophys. Res., 104, 30 937-30 946, https://doi.org/10.1029/1999JD900445.

, D. B. Stephenson, D. W. J. Thompson, T. J. Dunkerton, A. J. Charlton, and A. O'Neill, 2003: Stratospheric memory and skill of extended-range weather forecasts. Science, 301, 636640, https://doi.org/10.1126/science.1087143.

Bao, Q., J. Yang, Y. M. Liu, G. X. Wu, and B. Wang, 2010: Roles of anomalous Tibetan Plateau warming on the severe 2008 winter storm in central-southern China. Mon. Wea. Rev., 138, 2375-2384, https://doi.org/10.1175/2009MWR2950.1.

Barnston, A. G., and R. E. Livezey, 1987: Classification, seasonality and persistence of low-frequency atmospheric circulation patterns. Mon. Wea. Rev., 115, 1083-1126, https://doi.org/10.1175/ 1520-0493(1987)115\%3C1083:CSAPOL\%3E2.0.CO;2.

Beniston, M., 2004: The 2003 heat wave in Europe: A shape of things to come? An analysis based on Swiss climatological data and model simulations. Geophys. Res. Lett., 31, L02202, https://doi.org/10.1029/2003GL018857.

Brodzik, M., and R. Armstrong, 2013: Northern Hemisphere EASE-Grid 2.0 weekly snow cover and sea ice extent, version 4. National Snow and Ice Data Center, Boulder, CO, accessed 21 May 2020, http://nsidc.org/data/nsidc-0046.

Cai, M., S. Yang, H. Van den Dool, and V. Kousky, 2007: Dynamical implications of the orientation of atmospheric eddies: A local energetics perspective. Tellus, 59A, 127-140, https://doi.org/10.1111/ j.1600-0870.2006.00213.x.

Chen, S., and R. Wu, 2017: Interdecadal changes in the relationship between interannual variations of spring North Atlantic SST and Eurasian surface air temperature. J. Climate, 30, 37713787, https://doi.org/10.1175/JCLI-D-16-0477.1.

$\longrightarrow$, and _ 2018: Impacts of early autumn Arctic sea ice concentration on subsequent spring Eurasian surface air temperature variations. Climate Dyn., 51, 2523-2542, https:// doi.org/10.1007/s00382-017-4026-x.

, and L. Song, 2019: The leading interannual variability modes of winter surface air temperature over Southeast Asia. Climate Dyn., 52, 4715-4734, https://doi.org/10.1007/s00382-018-4406-x.

- B. Yu, and W. Chen, 2014: An analysis on the physical process of the influence of AO on ENSO. Climate Dyn., 42, 973989, https://doi.org/10.1007/s00382-012-1654-z.

$\longrightarrow, \mathrm{R}$. Wu, and Y. Liu, 2016: Dominant modes of interannual variability in Eurasian surface air temperature during boreal spring. J. Climate, 29, 1109-1125, https://doi.org/10.1175/JCLI-D-15-0524.1. , - _ L. L. Song, and W. Chen, 2018a: Combined influences of the Arctic Oscillation and the Scandinavia pattern on spring surface air temperature variations over Eurasia. J. Geophys. Res. Atmos., 123, 9410-9429, https://doi.org/10.1029/2018JD028685. 
, W. Chen, and S. Yao, 2018b: Enhanced linkage between Eurasian winter and spring dominant modes of atmospheric interannual variability since the early 1990s. J. Climate, 31, 3575-3595, https://doi.org/10.1175/JCLI-D-17-0525.1.

- — - L. Song, and W. Chen, 2019a: Interannual variability of surface air temperature over mid-high latitudes of Eurasia during boreal autumn. Climate Dyn., 53, 1805-1821, https:// doi.org/10.1007/s00382-019-04738-9.

,-- , and W. Chen, 2019b: Enhanced impact of Arctic sea ice change during boreal autumn on the following spring Arctic Oscillation since the mid-1990s. Climate Dyn., 53, 5607-5621, https://doi.org/10.1007/s00382-019-04886-y.

,,--- and B. Yu, 2020: Influence of winter Arctic sea ice concentration change on the El Niño-Southern Oscillation in the following winter. Climate Dyn., 54, 741-757, https:// doi.org/10.1007/S00382-019-05027-1.

Chen, Z., R. Wu, and W. Chen, 2014: Impacts of autumn Arctic sea ice concentration changes on the East Asian winter monsoon variability. J. Climate, 27, 5433-5450, https://doi.org/10.1175/JCLI-D-13-00731.1.

Cheung, H., W. Zhou, H. Mok, and M. Wu, 2012: Relationship between Ural-Siberian blocking and the East Asian winter monsoon in relation to the Arctic Oscillation and the El Niño-Southern Oscillation. J. Climate, 25, 4242-4257, https://doi.org/10.1175/JCLI-D-11-00225.1.

Cohen, J., and C. Fletcher, 2007: Improved skill of Northern Hemisphere winter surface temperature predictions based on land-atmosphere fall anomalies. J. Climate, 20, 4118-4132, https://doi.org/10.1175/JCLI4241.1.

— J. Furtado, M. Barlow, V. Alexeev, and J. Cherry, 2012: Arctic warming, increasing fall snow cover and widespread boreal winter cooling. Environ. Res. Lett., 7, 014007, https:// doi.org/10.1088/1748-9326/7/1/014007.

Czaja, A., and C. Frankignoul, 1999: Influence of the North Atlantic SST on the atmospheric circulation. Geophys. Res. Lett., 26, 2969-2972, https://doi.org/10.1029/1999GL900613.

— and - 2002: Observed impact of Atlantic SST anomalies on the North Atlantic Oscillation. J. Climate, 15, 606-623, https:// doi.org/10.1175/1520-0442(2002)015<0606:OIOASA $>2.0 . C O ; 2$.

_ , P. van der Vaart, and J. Marshall, 2002: A diagnostic study of the role of remote forcing in tropical Atlantic variability. J. Climate, 15, 3280-3290, https://doi.org/10.1175/1520-0442(2002)015<3280: ADSOTR $>2.0 . \mathrm{CO} ; 2$.

Duchon, C. E., 1979: Lanczos filtering in one and two dimensions. J. Appl. Meteor., 18, 1016-1022, https://doi.org/10.1175/15200450(1979)018<1016:LFIOAT $>2.0$. CO 2 .

Francis, J. A., and S. J. Vavrus, 2012: Evidence linking Arctic amplification to extreme weather in mid-latitudes. Geophys. Res. Lett., 39, L06801, https://doi.org/10.1029/2012GL051000.

Gámiz-Fortis, S. R., M. J. Esteban-Parra, D. Pozo-Vázquez, and Y. Castro-Díez, 2011: Variability of the monthly European temperature and its association with the Atlantic sea-surface temperature from interannual to multidecadal scales. Int. J. Climatol., 31, 2115-2140, https://doi.org/10.1002/joc.2219.

Gao, Y., and Coauthors, 2015: Arctic sea ice and Eurasian climate: A review. Adv. Atmos. Sci., 32, 92-114, https://doi.org/10.1007/ s00376-014-0009-6.

Gong, D. Y., S.-W. Wang, and J.-H. Zhu, 2001: East Asian winter monsoon and Arctic Oscillation. Geophys. Res. Lett., 28, 2073-2076, https://doi.org/10.1029/2000GL012311.

Gu, S. A., and X. Q. Yang, 2006: Variability of the northern circumpolar vortex and its association with climate anomaly in China (in Chinese). J. Meteor. Sci., 26, 135-142.

Ham, Y.-G., J.-S. Kug, J.-Y. Park, and F.-F. Jin, 2013: Sea surface temperature in the north tropical Atlantic as a trigger for
El Niño/Southern Oscillation events. Nat. Geosci., 6, 112-116, https://doi.org/10.1038/ngeo1686.

Honda, M., J. Inoue, and S. Yamane, 2009: Influence of low Arctic seaice minima on anomalously cold Eurasian winters. Geophys. Res. Lett., 36, L08707, https://doi.org/10.1029/2008GL037079.

Huang, B., and J. Shukla, 2005: Ocean-atmosphere interactions in the tropical and subtropical Atlantic Ocean. J. Climate, 18, 1652-1672, https://doi.org/10.1175/JCLI3368.1.

— , and Coauthors, 2017: Extended Reconstructed Sea Surface Temperature version 5 (ERSSTv5): Upgrades, validations, and intercomparisons. J. Climate, 30, 8179-8205, https://doi.org/ 10.1175/JCLI-D-16-0836.1.

Hurrell, J. W., 1995: Decadal trends in the North Atlantic Oscillation. Science, 269, 676-679, https://doi.org/10.1126/science.269.5224.676. , and H. van Loon, 1997: Decadal variations in climate associated with the North Atlantic Oscillation. Climatic Change at High Elevation Sites, H. F. Diaz et al., Eds., Springer, 69-94.

Kalnay, E., and Coauthors, 1996: The NCEP/NCAR 40-Year Reanalysis Project. Bull. Amer. Meteor. Soc., 77, 437-471, https://doi.org/ 10.1175/1520-0477(1996)077<0437:TNYRP > 2.0.CO;2.

Klein, S. A., B. J. Soden, and N.-C. Lau, 1999: Remote sea surface temperature variations during ENSO: Evidence for a tropical atmospheric bridge. J. Climate, 12, 917-932, https://doi.org/ 10.1175/1520-0442(1999)012<0917:RSSTVD>2.0.CO;2.

Labat, D., Y. Goddéris, J. L. Probst, and J. L. Guyot, 2004: Evidence for global runoff increase related to climate warming. Adv. Water Resour., 27, 631-642, https://doi.org/10.1016/j.advwatres.2004.02.020.

Lau, N. C., 1988: Variability of the observed midlatitude storm tracks in relation to low-frequency changes in the circulation pattern. J. Atmos. Sci., 45, 2718-2743, https://doi.org/10.1175/ 1520-0469(1988)045<2718:VOTOMS > 2.0.CO;2.

Li, F., and H. J. Wang, 2013: Relationship between Bering Sea ice cover and East Asian winter monsoon year-to-year variations. $A d v$. Atmos. Sci., 30, 48-56, https://doi.org/10.1007/s00376-012-2071-2.

- — - and Y. Q. Gao, 2017: Stratospheric precursor of nonuniform variation in early spring surface temperature over Eurasia. J. Meteor. Res., 31, 389-396, https://doi.org/10.1007/ s13351-017-6055-0.

Li, J. P., and Z. W. Wu, 2012: Importance of autumn Arctic sea ice to northern winter snowfall. Proc. Natl. Acad. Sci. USA, 109, E1898, https://doi.org/10.1073/pnas.1205075109.

Li, X., Z. W. Wu, and Y. Li, 2019: A link of China warming hiatus with the winter sea ice loss in Barents-Kara Seas. Climate Dyn., 53, 2625-2642, https://doi.org/10.1007/s00382-019-04645-z.

Limpasuvan, V., and D. L. Hartmann, 1999: Eddies and the annular modes of climate variability. Geophys. Res. Lett., 26, 31333136, https://doi.org/10.1029/1999GL010478.

Liu, J. P., J. A. Curry, H. J. Wang, M. R. Song, and R. M. Horton, 2012: Impact of declining Arctic sea ice on winter snowfall. Proc. Natl. Acad. Sci. USA, 109, 4074-4079, https://doi.org/ 10.1073/pnas.1114910109.

Liu, X., and M. Yanai, 2001: Relationship between the Indian monsoon rainfall and the tropospheric temperature over the Eurasian continent. Quart. J. Roy. Meteor. Soc., 127, 909-937, https://doi.org/10.1002/qj.49712757311.

Lorenz, D. J., and D. L. Hartmann, 2003: Eddy-zonal flow feedback in the Northern Hemisphere winter. J. Climate, 16, 1212-1227, https:// doi.org/10.1175/1520-0442(2003)16<1212:EFFITN>2.0.CO;2.

Lu, C. H., and Y. H. Ding, 2015: Analysis of isentropic potential vorticities for the relationship between stratospheric anomalies and the cooling process in China. Sci. Bull., 60, 726-738, https://doi.org/10.1007/S11434-015-0757-4. 
Matsuura, K., and C. J. Willmott, 2009: Terrestrial air temperature: 19002008 gridded monthly time series (version 4.01). University of Delaware, http://www.esrl.noaa.gov/psd/data/gridded/data.UDel_ AirT_Precip.html.

Miyazaki, C., and T. Yasunari, 2008: Dominant interannual and decadal variability of winter surface air temperature over Asia and the surrounding oceans. J. Climate, 21, 1371-1386, https:// doi.org/10.1175/2007JCLI1845.1.

Nakamura, T., K. Yamazaki, K. Iwamoto, M. Honda, Y. Miyoshi, Y. Ogawa, and J. Ukita, 2015: A negative phase shift of the winter $\mathrm{AO} / \mathrm{NAO}$ due to the recent Arctic sea-ice reduction in late autumn. J. Geophys. Res. Atmos., 120, 3209-3227, https:// doi.org/10.1002/2014JD022848.

North, G. R., T. L. Bell, R. F. Cahalan, and F. J. Moeng, 1982: Sampling errors in the estimation of empirical orthogonal functions. Mon. Wea. Rev., 110, 699-706, https://doi.org/ 10.1175/1520-0493(1982)110<0699:SEITEO > 2.0.CO;2.

Otomi, Y., Y. Tachibana, and T. Nakamura, 2013: A possible cause of the AO polarity reversal from winter to summer in 2010 and its relationship to hemispheric extreme summer weather. Climate Dyn., 40, 1939-1947, https://doi.org/10.1007/s00382012-1386-0.

Pan, L. L., 2005: Observed positive feedback between the NAO and the North Atlantic SSTA tripole. Geophys. Res. Lett., 32, L06707, https://doi.org/10.1029/2005GL022427.

Park, H., and J. Ahn, 2015: Combined effect of the Arctic Oscillation and the western Pacific pattern on East Asia winter temperature. Climate Dyn., 46, 3205-3221, https://doi.org/ 10.1007/s00382-015-2763-2.

Peng, S., W. A. Robinson, and S. Li, 2003: Mechanisms for the NAO responses to the North Atlantic SST tripole. J. Climate, 16, 1987-2004, https://doi.org/10.1175/1520-0442(2003)016<1987: MFTNRT $>2.0 . \mathrm{CO} ; 2$.

Rayner, N. A., D. E. Parker, E. B. Horton, C. K. Folland, L. V. Alexander, D. P. Rowell, E. C. Kent, and A. Kaplan, 2003: Global analyses of sea surface temperature, sea ice, and night marine air temperature since the late nineteenth century. J. Geophys. Res., 108, 4407, https://doi.org/10.1029/2002JD002670.

Saravanan, R., and P. Chang, 2000: Interaction between tropical Atlantic variability and El Niño-Southern Oscillation. J. Climate, 13, 2177-2194, https://doi.org/10.1175/1520-0442(2000)013<2177: IBTAVA $>2.0 . \mathrm{CO} ; 2$.

Smith, T. M., R. W. Reynolds, T. C. Peterson, and J. Lawrimore, 2008: Improvements to NOAA's historical merged landocean surface temperature analysis (1880-2006). J. Climate, 21, 2283-2296, https://doi.org/10.1175/2007JCLI2100.1.

Stott, P. A., D. A. Stone, and M. R. Allen, 2004: Human contribution to the European heatwave of 2003. Nature, 432, 610 614, https://doi.org/10.1038/nature03089.

Sun, C., S. Yang, W. J. Li, R. Zhang, and R. Wu, 2016: Interannual variations of the dominant modes of East Asian winter monsoon and possible links to Arctic sea ice. Climate Dyn., 47, 481-491, https://doi.org/10.1007/S00382-015-2851-3.

Sun, Y. T., S. Y. Wang, and Y. Q. Yang, 1983: Studies on cool summer and crop yield in Northeast China (in Chinese). Acta Meteor. Sin., 41, 313-321.

Tang, Q., X. Zhang, X. Yang, and J. A. Francis, 2013: Cold winter extremes in northern continents linked to Arctic sea ice loss. Environ. Res. Lett., 8, 014036, https://doi.org/10.1088/17489326/8/1/014036.
Thompson, D. W., and J. M. Wallace, 1998: The Arctic Oscillation signature in the wintertime geopotential height and temperature fields. Geophys. Res. Lett., 25, 1297-1300, https://doi.org/ 10.1029/98GL00950.

, and — 2000: Annular modes in the extratropical circulation. Part I: Month-to-month variability. J. Climate, 13, 1000-1016, https:// doi.org/10.1175/1520-0442(2000)013<1000:AMITEC>2.0.CO;2.

Vihma, T., 2014: Effects of Arctic sea ice decline on weather and climate: A review. Surv. Geophys., 35, 1175-1214, https:// doi.org/10.1007/s10712-014-9284-0.

Wang, X., S. Piao, P. Ciais, J. Li, P. Friedlingstein, C. Koven, and A. Chen, 2011: Spring temperature change and its implication in the change of vegetation growth in North America from 1982 to 2006. Proc. Natl. Acad. Sci. USA, 108, 1240-1245, https://doi.org/10.1073/pnas.1014425108.

Wei, K., W. Chen, and W. Zhou, 2011: Changes in the East Asian cold season since 2000. Adv. Atmos. Sci., 28, 69-79, https:// doi.org/10.1007/s00376-010-9232-y.

Wu, B.-Y., J.-Z. Su, and R.-H. Zhang, 2011: Effects of autumnwinter Arctic sea ice on winter Siberian high. Chin. Sci. Bull., 56, 3220-3228, https://doi.org/10.1007/s11434-011-4696-4.

$\mathrm{Wu}, \mathrm{R}$., and S. Chen, 2016: Regional change in snow water equivalent-surface air temperature relationship over Eurasia during boreal spring. Climate Dyn., 47, 2425-2442, https:// doi.org/10.1007/s00382-015-2972-8.

- S. Yang, S. Liu, L. Sun, Y. Lian, and Z. Gao, 2010: Changes in the relationship between northeast China summer temperature and ENSO. J. Geophys. Res., 115, D21107, https://doi.org/ 10.1029/2010JD014422.

Wu, Z. W., and P. Zhang, 2015: Interdecadal variability of the mega-ENSO-NAO synchronization in winter. Climate Dyn., 45, 1117-1128, https://doi.org/10.1007/s00382-014-2361-8.

_, B. Wang, J. Li, and F. F. Jin, 2009: An empirical seasonal prediction model of the East Asian summer monsoon using ENSO and NAO. J. Geophys. Res., 114, D18120, https:// doi.org/10.1029/2009JD011733.

— X. Li, Y. J. Li, and Y. Li, 2016: Potential influence of Arctic sea ice to the inter-annual variations of East Asian spring precipitation. J. Climate, 29, 2797-2813, https://doi.org/10.1175/JCLID-15-0128.1.

Yang, X., X. Yuan, and M. Ting, 2016: Dynamical link between the Barents-Kara Sea ice and the Arctic Oscillation. J. Climate, 29, 5103-5122, https://doi.org/10.1175/JCLI-D-15-0669.1.

Yao, P. Z., 1995: The climate features of summer low temperature cold damage in northeast China during recent 40 years (in Chinese). J. Catastrophol., 10, 51-56.

Zhang, P., B. Wang, and Z. Wu, 2019a: Weak El Niño and winter climate in the mid-to high latitude of Eurasia. J. Climate, 32, 405-421, https://doi.org/10.1175/JCLI-d-17-0583.1.

- Z. Wu, and J. Li, 2019b: Reexamining the relationship of La Niña and the East Asian winter monsoon. Climate Dyn., 53, 779-791, https://doi.org/10.1007/s00382-019-04613-7.

Zhao, W., S. F. Chen, W. Chen, S. L. Yao, D. Nath, and B. Yu, 2019: Interannual variations of the rainy season withdrawal of the monsoon transitional zone in China. Climate Dyn., 53, 20312046, https://doi.org/10.1007/s00382-019-04762-9.

Zveryaev, I. I., and S. K. Gulev, 2009: Seasonality in secular changes and interannual varibility of European air temperature during the twentieth century. J. Geophys. Res., 114, D02110, https://doi.org/10.1029/2008JD010624. 